\title{
A Spinal Mechanism Related to Left-Right Symmetry Reduces Cutaneous Reflex Modulation Independently of Speed During Split-Belt Locomotion
}

\author{
Marie-France Hurteau and ${ }^{-A}$ Alain Frigon \\ Department of Pharmacology-Physiology, Faculty of Medicine and Health Sciences, Université de Sherbrooke, Sherbrooke, Quebec J1H 5N4, Canada
}

Task- and phase-dependent reflex modulation during locomotion is well established, but we do not know the signals driving this modulation. To determine whether signals related to left-right symmetry of the locomotor pattern modulate cutaneous reflexes, we stimulated the superficial peroneal nerve in five intact female cats and in four spinal-transected cats (spinal cats, two males and two females) during split-belt locomotion at different left-right speeds. We compared cutaneous reflexes evoked in three ipsilateral and two contralateral hindlimb muscles during split-belt locomotion with those evoked during tied-belt (equal left-right speeds) locomotion at matched speeds of the slow and fast limbs. Our results showed similar phase-dependent modulation of cutaneous reflexes during tied-belt and split-belt locomotion in intact and spinal cats. During tied-belt locomotion in intact cats, an increase in speed significantly increased reflex modulation from minimum to maximum values, whereas in spinal cats, we observed a significant decrease. However, in all muscles of intact and spinal cats, split-belt locomotion significantly reduced reflex modulation compared with tied-belt locomotion independently of which limb was stepping on the slow or fast belt. Additionally, reflex modulation correlated more with spatial left-right symmetry, as opposed to a temporal one, in intact and spinal cats. Our results indicate that signals related to left-right symmetry reduce cutaneous reflex modulation independently of speed via a spinal mechanism. We propose that asymmetric sensory feedback from the left and right legs alters the state of the spinal network, thereby reducing cutaneous reflexes to prevent inputs from destabilizing a potentially unstable pattern.

Key words: locomotion; reflex; spinal cord; split-belt

Significance Statement

When we contact an obstacle during walking, receptors in the skin send signals to the CNS to alter the trajectory of the leg to maintain balance. This response, or reflex, is different when the leg is in the air and when it is contacting the ground. The reflex also differs when we walk at different speeds. Here, we investigated this reflex when the left and right legs were walking at different speeds on a split-belt treadmill in cats. We show that the reflex is smaller during split-belt locomotion compared with when both legs are walking at equal speeds. We propose that the spinal locomotor network controlling walking reduces the reflex response to optimize balance when gait is unstable.

\section{Introduction}

During locomotion, receptors located in the skin allow the body to interact with the environment (Panek et al., 2014). These in-

Received April 28, 2018; revised 0ct. 4, 2018; accepted 0ct. 6, 2018.

Author contributions: M.F.H. wrote the first draft of the paper; M.-F.H. and A.F. edited the paper; M.F.H. and A.F. designed research; M.-F.H. and A.F. performed research; M.-F.H. and A.F. analyzed data; M.F.H. and A.F. wrote the paper.

This work was supported by the Natural Sciences and Engineering Research Council of Canada (NSERC Discovery Grant RGPIN-2016-03790), the Fonds de Recherche du Québec-Natures et Technologies (Project Team Grant (182035), and the American Physiological Society (Arthur C. Guyton Award for Excellence in Integrative Physiology and the Beverly Petterson Bishop Award for Excellence in Neuroscience to A.F.). M.-F.H. was supported by a doctoral scholarship from NSERC. We thank Philippe Drapeau (Rossignol and Drew laboratories, Université de Montréal) for providing data acquisition and analysis software.

The authors declare no competing financial interests.

Correspondence should be addressed to Dr. Alain Frigon, Université de Sherbrooke, 3001, 12e Avenue Nord, Department of Pharmacology-Physiology, Faculty of Medicine and Health Sciences, Sherbrooke, Quebec J1H 5N4, Canada. E-mail: alain.frigon@usherbrooke.ca. teractions are crucial to ensure dynamic balance and smooth forward progression. For example, in cats and humans, when the foot contacts an obstacle during the swing phase, cutaneous afferents send inputs to spinal neurons to modify the trajectory of the contacted limb and to reinforce contralateral limb support, which is termed the stumbling corrective reaction (Forssberg et al., 1977; Prochazka et al., 1978; Forssberg, 1979; Schillings et al., 1996; Van Wezel et al., 1997; Zehr and Stein, 1999; Quevedo et al., 2005a,b). The stumbling corrective reaction, or cutaneous reflexes consistent with it, is present in the hindlimbs of cats with a complete spinal transection (spinal cats), indicating that it is organized within the spinal cord (Forssberg et al., 1975, 1977;

https://doi.org/10.1523/JNEUROSCl.1082-18.2018

Copyright $\odot 2018$ the authors $\quad 0270-6474 / 18 / 3810314-15 \$ 15.00 / 0$ 
Frigon and Rossignol, 2008a; Hurteau et al., 2017). Moreover, in cats and humans, reflexes evoked by stimulating the superficial peroneal (SP) nerve, which supplies the skin of the foot dorsum, are observed in the four limbs, indicating that the stumbling corrective reaction is a whole-body response (Haridas and Zehr, 2003; Haridas et al., 2006; Hurteau et al., 2018).

Several cat and human locomotion studies have shown that mechanisms modulate cutaneous reflexes according to task and movement phase (for review, see Burke, 1999; Zehr and Stein, 1999; Duysens et al., 2004; Rossignol et al., 2006). The flexible modulation of cutaneous reflexes reflects their functional importance for shaping locomotor output in response to external cues. We also recently showed that locomotor speed influences cutaneous reflex modulation in spinal cats (Hurteau et al., 2017). We observed the largest reflex modulation at intermediate speeds and the smallest modulation at the slowest and fastest speeds tested. Interestingly, the reduction in cutaneous reflex modulation correlated with an increase in the spatial asymmetry between the legs. Therefore, it appears that a signal related to left-right asymmetry reduces cutaneous reflex modulation via a spinal mechanism.

One approach to exploring this hypothesis is by evoking and recording cutaneous reflexes during split-belt locomotion, in which we can control the speed of each leg independently. Splitbelt locomotion generates temporal and spatial asymmetries between the slow and fast limbs in cats and humans (Kulagin and Shik, 1970; Forssberg et al., 1980; Halbertsma, 1983; Dietz et al., 1994; Prokop et al., 1995; Reisman et al., 2005; Torres-Oviedo et al., 2011; Frigon et al., 2013, 2015, 2017; D’Angelo et al., 2014; Hoogkamer et al., 2014; Kuczynski et al., 2017), reproduces some aspects of stepping along a curved path (Courtine and Schieppati, 2003a,b), and simulates a limping gait, which can be considered an unstable form of locomotion (Duysens et al., 2004, 2012; McFadyen et al., 2009; Hoogkamer et al., 2015). During prolonged split-belt locomotion in humans, there is a return, or adaptation, of left-right symmetry in interlimb parameters such as double support periods and step lengths (Reisman et al., 2005). However, in intact and spinal cats, we did not observe adaptation of interlimb parameters during prolonged split-belt locomotion (Kuczynski et al., 2017), which makes the cat model particularly interesting to investigate reflex modulation in prolonged asymmetric conditions. The modulation of reflexes during split-belt locomotion, however, has received little attention. Duysens et al. (2004) used split-belt locomotion to activate the ankle flexor tibialis anterior during stance in humans and showed that suppressive responses evoked by sural nerve stimulation persisted during the support phase.

In the present study, we used split-belt locomotion to determine whether asymmetric stepping modulates cutaneous reflexes in muscles ipsilateral and contralateral to the stimulation in both intact and spinal cats compared with matched speeds in tied-belt conditions. We hypothesize that split-belt locomotion reduces cutaneous reflex modulation compared with matched tied-belt speeds in both intact and spinal cats, consistent with a spinal mechanism. We also hypothesize that this reduction correlates more importantly with a spatial left-right asymmetry in the locomotor pattern, as opposed to a temporal one.

\section{Materials and Methods}

Ethical approval. The Animal Care Committee of the Universite de Sherbrooke approved the experimental procedures (Protocol 273-15) and were in accordance with policies and directives of the Canadian Council on Animal Care. We obtained the current dataset from 5 adult $(>9$ months) female intact cats and 4 adult spinal cats ( 2 females and 2 males), weighing between 2.5 and $5.0 \mathrm{~kg}$. As part of our effort to reduce the number of research animals, we used all cats in other projects to answer other scientific questions (D'Angelo et al., 2014; Frigon et al., 2014, 2017; Dambreville et al., 2015; Hurteau et al., 2015, 2017, 2018; Dambreville et al., 2016; Kuczynski et al., 2017).

General surgical procedures. We performed the implantation and spinal transection surgeries under aseptic conditions in an operating room with sterilized equipment, as described previously (Hurteau et al., 2017, 2018). Before surgery, we sedated and induced the animals with an intramuscular injection of butorphanol $(0.4 \mathrm{mg} / \mathrm{kg})$, acepromazine $(0.1 \mathrm{mg} /$ $\mathrm{kg})$, and glycopyrrolate $(0.01 \mathrm{mg} / \mathrm{kg})$ and an intramuscular injection of ketamine/diazepam $(0.11 \mathrm{ml} / \mathrm{kg}$ in a $1: 1 \mathrm{ratio})$, respectively. We then shaved the cats and cleaned their skin with chlorhexidine soap. We then anesthetized the cats with isoflurane (1.5-3\%) by mask followed by endotracheal intubation. We adjusted isoflurane concentration by monitoring cardiac and respiratory rates and limb withdrawal with pressure applied to the paw and jaw tone. We monitored body temperature with a rectal thermometer and maintained it between $35^{\circ} \mathrm{C}$ and $37^{\circ} \mathrm{C}$ during surgery with a water-filled heating pad placed under the animal and an infrared lamp $\sim 50 \mathrm{~cm}$ over it. At the end of surgery, we administered an antibiotic (Convenia, $0.1 \mathrm{ml} / \mathrm{kg}$ ) subcutaneously. For analgesia, we taped a transdermal fentanyl patch $(25 \mu \mathrm{g} / \mathrm{h})$ to the back of the animal $2-3 \mathrm{~cm}$ rostral to the base of the tail and subcutaneously injected buprenorphine $(0.01 \mathrm{mg} / \mathrm{kg})$, a fast-acting analgesic, at the end of the surgery and $\sim 7 \mathrm{~h}$ later. Until they regained consciousness, we kept the animals in an incubator under close supervision. We removed the fentanyl patch $5 \mathrm{~d}$ after surgery. At the end of the experiments, we injected a lethal dose of pentobarbital through the animal's cephalic vein.

Implantation procedure. To record muscle activity (EMG), we directed pairs of Teflon-insulated multistrand fine wires (AS633; Cooner Wire) subcutaneously from a head-mounted 34-pin connector (Omnetics) and sowed them into the belly of selected hindlimb muscles. During implantation, we electrically stimulated each muscle through the appropriate head connector channel to verify electrode placement. The current data include EMG from the following muscles: semitendinosus (St, knee flexor/hip extensor), vastus lateralis (VL, knee extensor), and lateral gastrocnemius (LG, ankle extensor/knee flexor). During experiments, EMGs were preamplified ( $10 \times$, custom-made system), band-pass filtered ( 30 $1000 \mathrm{~Hz}$ ), and amplified (100-5000×) using a 16-channel amplifier (AM Systems 3500). EMG data were digitized $(5000 \mathrm{~Hz})$ with a National Instruments card (NI 6032E) acquired with custom-made acquisition software, and stored on a computer. For bipolar nerve stimulation, we directed pairs of Teflon-insulated multistrand fine wires (AS633; Cooner Wire) subcutaneously from a head-mounted four-pin connector (Omnetics). We then fixed the wires inside silicon tubes $(\sim 1 \mathrm{~cm})$ and placed them around the left and right SP nerves just proximal to the ankle joint. The SP nerve is purely sensory (cutaneous) at this level (Bernard et al., 2007).

Spinal transection and locomotor training. In four cats, we transected the spinal cord at low thoracic levels. We first made a small incision of the skin over the 12th and 13th thoracic vertebrae, which correspond to the same spinal segments in cats (Eldridge, 1984). After carefully setting aside muscle and connective tissue, we performed a small dorsal laminectomy. We applied lidocaine (xylocaine) topically and injected it within the spinal cord before transecting the spinal cord with surgical scissors. We inserted hemostatic material (Spongostan) within the gap before sewing back muscles and skin in anatomical layers. After spinal transection, we manually expressed the bladder of spinal cats one to two times daily. Experienced personnel closely monitored spinal cats on a daily basis for the duration of the study.

A week after spinal transection, we started training cats on a treadmill so that they recovered hindlimb locomotion. We performed five training sessions per week that lasted 20-30 min each. At first, two experimenters moved the hindlimbs over the moving treadmill belt to reproduce a locomotor pattern, with one of the experimenters holding the tail for support. The forelimbs were positioned on a fixed platform located $1 \mathrm{~cm}$ above the belt and a Plexiglas separator was placed between the hindlimbs to prevent crossing. After a few days of training, we elicited stepping movements by stimulating the skin of the perineum. Over a few additional weeks, cats recovered full weight-bearing hindlimb locomotion with 
consistent plantar placement. During data collection, an experimenter held the tail to provide equilibrium.

Experimental design. Cats performed experiments on a treadmill with two independently controlled running surfaces $120 \mathrm{~cm}$ long and $30 \mathrm{~cm}$ wide (Bertec). We initially trained intact cats to step on the treadmill at various tied-belt and split-belt speeds using food and affection as reward. During experiments, we stimulated the left or right SP nerve while cats performed one of four locomotor conditions: Tied-slow, Tied-fast, Splitslow, and Split-fast. The terms "slow" and "fast" always refer to the ipsilateral limb (the stimulated limb). Intact cats performed tied-belt locomotion at $0.4 \mathrm{~m} / \mathrm{s}$ (Tied-slow) and $0.7 \mathrm{~m} / \mathrm{s}$ (Tied-fast), whereas spinal cats performed it at $0.4 \mathrm{~m} / \mathrm{s}$ (Tied-slow) and $0.6 \mathrm{~m} / \mathrm{s}$ (Tied-fast). We used the same speeds during split-belt locomotion for the slow and fast limbs. In the Split-slow condition of intact cats, the ipsilateral and contralateral limbs stepped at $0.4 \mathrm{~m} / \mathrm{s}$ and $0.7 \mathrm{~m} / \mathrm{s}$, respectively, while in the Split-fast condition the ipsilateral and contralateral limbs stepped at 0.7 $\mathrm{m} / \mathrm{s}$ and $0.4 \mathrm{~m} / \mathrm{s}$, respectively. In the Split-slow condition of spinal cats, the ipsilateral and contralateral limbs stepped at $0.4 \mathrm{~m} / \mathrm{s}$ and $0.6 \mathrm{~m} / \mathrm{s}$, respectively, while in the Split-fast condition the ipsilateral and contralateral limbs stepped at $0.6 \mathrm{~m} / \mathrm{s}$ and $0.4 \mathrm{~m} / \mathrm{s}$, respectively. We used 0.6 $\mathrm{m} / \mathrm{s}$ for the fast speed in spinal cats because we found the pattern inconsistent during split-belt locomotion at faster speeds, with extra steps taken by the fast limb.

During experiments, we evoked cutaneous reflexes by delivering electrical stimuli to the SP nerve with a Grass S88 stimulator using a single pulse of $0.2 \mathrm{~ms}$ duration. At the beginning of each experiment, we determined the motor threshold, defined as the lowest intensity required for a small short latency $(8-10 \mathrm{~ms})$ excitatory response in the ipsilateral St muscle $50 \mathrm{~ms}$ following its burst onset. We then set stimulation intensity at 1.2 times the motor threshold for the rest of the experiment. In each locomotor condition, we delivered 120-150 stimuli pseudorandomly every two to four locomotor cycles at varying delays relative to an ipsilateral hindlimb extensor burst onset to evoke responses at different times during the step cycle. The detection of the extensor burst to trigger the stimulation is based on a threshold and as the EMG activity varies slightly from burst to burst, the specified delays can also vary. This affects the number of stimuli, or responses, that fall in each bin. We obtained a minimum of two stimuli per bin in each condition for all cats. Each locomotor condition tested lasted 4-8 min. For a given nerve stimulation, we collected data for all four locomotor conditions within a single session. At the end of each session, we confirmed that the motor threshold remained stable.

Reflex analysis. We recently described the procedure to quantify reflexes (Hurteau et al., 2017, 2018). Briefly, we synchronized the step cycle to an extensor burst onset (VL or LG) in the stimulated limb (the ipsilateral limb). We tagged cycles as stimulated or control (nonstimulated) and divided them into 10 subphases (bins) of equal duration. We removed sections where the cat stepped irregularly, based on EMG and video data. In cycles with stimulation, we used the onset of the stimulus as the reference for the start of the cycle. We averaged responses in each bin. The control cycles provided a baseline locomotor EMG (blEMG) in each bin. We superimposed the averaged responses on blEMG to show how they deflect from the normal background of EMG. To quantify reflex responses, we used predefined latencies as guidelines (Duysens and Stein, 1978; Duysens and Loeb, 1980; Pratt et al., 1991; Loeb, 1993) and 95\% confidence intervals to set a window at the onset and offset of evoked responses, defined as prominent negative or positive deflections away from the blEMG.

Based on the terminology introduced by Duysens and Loeb (1980), we termed short-latency $(\sim 8-10 \mathrm{~ms})$ excitatory and inhibitory responses as $\mathrm{P} 1$ and N1 responses, respectively, and midlatency ( $\sim 20-25 \mathrm{~ms})$ excitatory responses as $\mathrm{P} 2$ responses. We also classified responses in the contralateral VL as P1 because they had onsets $<18 \mathrm{~ms}$, which is the minimal latency for spino-bulbo-spinal reflexes in cats (Shimamura and Livingston, 1963). We rectified and integrated the EMG of reflex responses from onset to offset and then subtracted the blEMG within the same window, thus providing a net value. We then divided this net value by the blEMG to provide a normalized measure of reflex amplitude. The division is required to determine whether changes in reflex responses across the cycle are independent of changes in blEMG activity (Matthews, 1986; Duysens et al., 1993; Frigon and Rossignol, 2008a; Frigon et al., 2009; Hurteau et al., 2017). To illustrate the modulation of reflexes by phase and condition (tied-belt and split-belt conditions), we normalized reflexes response in each muscle to the maximal value obtained in one of the four conditions. We also calculated a modulation index by measuring the difference between the largest and smallest responses out of the 10 bins for each condition (Hurteau et al., 2017). Because we observed inhibitory (N1) responses in some phases, which we considered negative values, and excitatory (P1) responses in other phases, the modulation index could exceed $100 \%$ in some muscles.

Data acquisition and analysis. We used two cameras (Basler AcA640$100 \mathrm{gm}$ ) to capture the videos of the left and right sides of the animals at $60 \mathrm{frames} / \mathrm{s}$ with a spatial resolution of $640 \times 480$ pixels. A custom-made Labview program acquired images and synchronized them with EMG data. We analyzed videos offline at 60 frames/s using custom-made software. We determined paw contact and liftoff by visual inspection for the four limbs in intact cats and for the hindlimbs in spinal cats. We defined paw contact as the first frame where the paw made visible contact with the treadmill surface and liftoff as the most caudal displacement of the limb. We measured cycle duration from successive paw contacts of the same limb; stance duration corresponded to the interval of time from paw contact to liftoff. Swing duration corresponded to cycle duration minus stance duration.

To determine how the locomotor pattern deviates from perfect leftright symmetry on a step-by-step basis, we measured a temporal and a spatial phasing index (Hurteau et al., 2017). We measured the temporal phase interval as the interval of time between stance onsets of the ipsilateral and contralateral hindlimbs divided by ipsilateral hindlimb cycle duration (Fig. 1A). We then measured the temporal phasing index by calculating the absolute deviation of the temporal phase interval from a perfect symmetry of 0.5 . For the spatial phasing index, we first measured stride length as the horizontal distance traveled from stance offset to onset plus the distance traveled by the opposite treadmill belt during the swing phase, which corresponds to swing duration multiplied by treadmill speed (Fig. 1B) (Goetz et al., 2012; Thibaudier and Frigon, 2014; Harnie et al., 2018). We then measured step length as the distance between the leading and trailing limb at stance onset of the leading limb (Hoogkamer et al., 2014). We measured stride and step lengths for the ipsilateral hindlimb. We then measured a spatial analog of the temporal phase interval, the gap interval, by dividing step length by stride length (Abourachid et al., 2007; Thibaudier and Frigon, 2014). We measured the spatial phasing index by calculating the absolute deviation of the gap interval from a perfect symmetry of 0.5 .

Statistical analysis. We quantified reflex responses in the ipsilateral St, VL, and LG, as well as in the contralateral VL and LG. In three of five intact cats and in two of four spinal cats, both the left and right SP nerves evoked responses. We treated responses evoked by left and right nerves separately and pooled them for statistical analysis $(n=8$ and $n=6$ nerves stimulated for five intact and four spinal cats, respectively). To assess phase-dependent modulation, we performed a one-factor (phase) repeated-measures ANOVA on short- and midlatency responses for pooled data. To compare cycle and stance durations across conditions and between limbs, we performed a two-factor (condition, limb) repeated-measures ANOVA for pooled data. We also determined whether locomotor condition affected the temporal and gap intervals, the temporal and spatial phasing indexes, as well as reflex modulation indexes using a one-factor (condition) repeated-measures ANOVA for pooled data. For temporal and spatial measures and modulation indexes, we used pairwise comparisons if there was a significant main effect and/or interaction of the repeated-measures ANOVAs. We also measured Pearson's correlation coefficient $(r)$ between the modulation index of $\mathrm{P} 1$ responses of the ipsilateral St and the temporal and spatial phasing indexes. We considered an $\alpha$-error of $p<0.05$ as significant for all tests.

We did not adjust the $\alpha$ level for multiple comparisons. We followed the recommendation of Rothman (1990) for not correcting for multiple comparisons, in contrast to other views (Greenland and Robins, 1991; Poole, 1991; Greenland, 2008). However, even proponents of adjusting for multiple comparisons agree with Rothman's recommendation when 
A

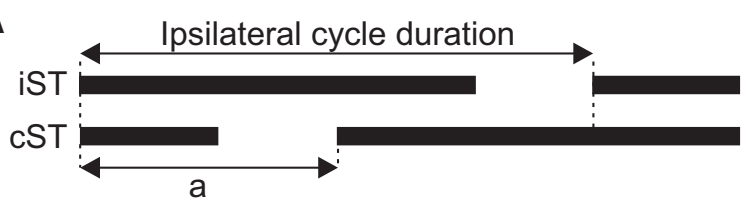

$\mathbf{a}=$ Time interval between iST and cST onsets

Temporal phase interval $=\mathrm{a} /$ Ipsilateral cycle duration

B

Stance offset

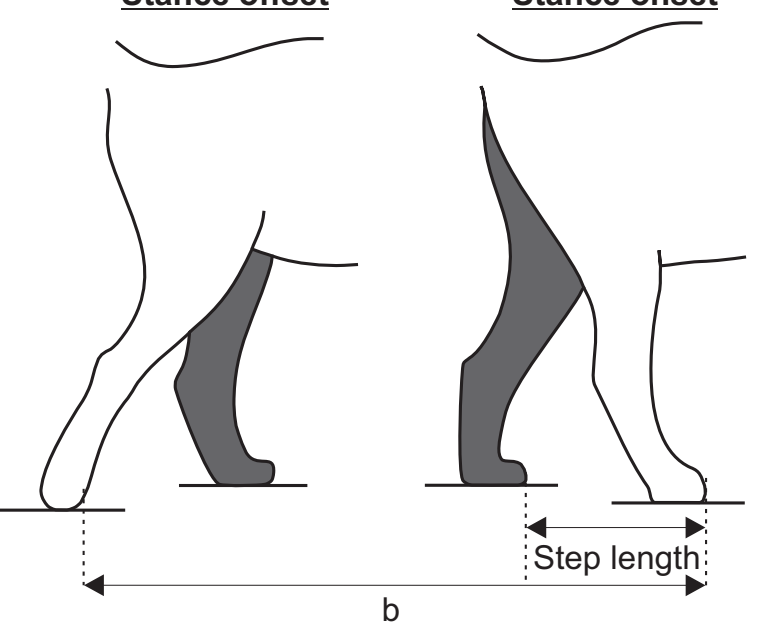

$\mathbf{b}=$ Horizontal distance traveled between stance onset and offset

Stride length $=b+($ swing duration $x$ treadmill speed of contralateral limb)

Gap interval = step length $/$ stride length

Figure 1. Measurements of temporal and spatial phase intervals. A, Measurement of the temporal phase interval using the onsets of the ipsilateral (iST) and contralateral (CST) stance phases. $\boldsymbol{B}$, Measurement of the gap interval using step length and stride length. The figure was modified with permission from Harnie et al. (2018).

A
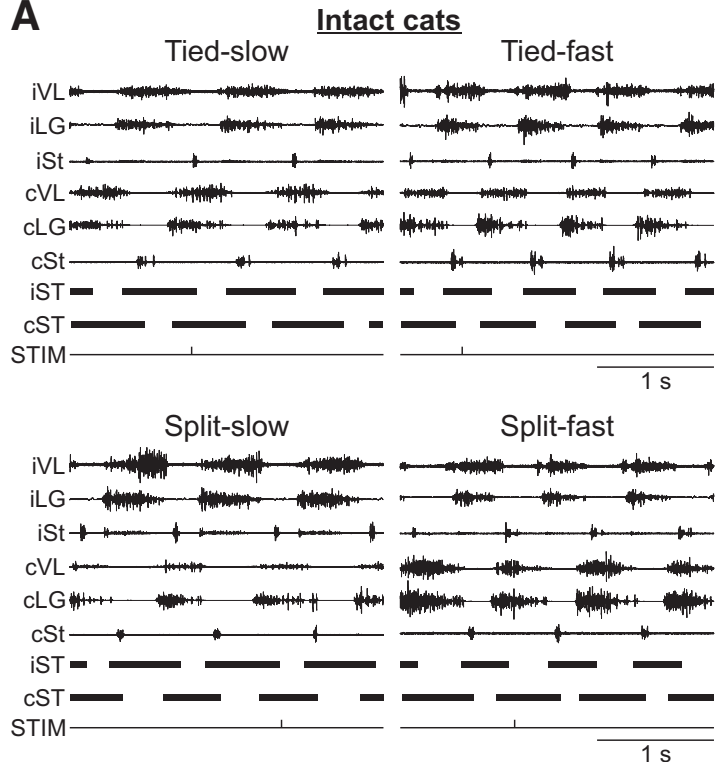

the objective of the analysis is to scientifically report and interpret the data (Greenland and Robins, 1991). Implicit in the assumption that a correction for multiple corrections is needed is that the associations between variables in the dataset are manifestations of random processes, or chance (Rothman, 1990; Greenland and Robins, 1991). Although this presumption may hold true for certain associations (Greenland and Robins, 1991), we do not believe it is valid when considering the association between spatiotemporal variables or reflex amplitude and speed/leftright speed differences. In this study, we believe that it was more important to avoid false negatives (type II errors) than false positives (type I errors). We could have applied the recommendation of lowering the $p$ threshold to 0.005 (Ioannidis, 2018) and, indeed, many of our reported differences would have remained significant; however, other potentially important physiological relationships in the data would have been obscured.

\section{Results}

Modulation of the pattern during tied-belt and split-belt locomotion

In the present study, we evoked and compared cutaneous reflexes at two speeds during tied-belt locomotion (Tied-slow, Tied-fast) and in the slow (Split-slow) and fast (Split-fast) limbs during split-belt locomotion in intact and spinal cats. Note again that "slow" and "fast" refer to the speed of the ipsilateral limb. To address the physiological role of cutaneous reflex responses, it was first important to characterize the pattern during tied-belt and split-belt locomotion.

Figure 2 shows EMG waveforms of the muscles studied in the present study along with the stance phases of the hindlimbs in a representative intact (Fig. 2A) and spinal (Fig. 2B) cat during tied-belt and split-belt locomotion. Note that the EMGs for a given muscle are at the same vertical scale in all four panels. In the intact and spinal cat, increasing treadmill speed during tied-belt locomotion reduced stance phase and extensor burst durations bilaterally. During split-belt locomotion, ipsilateral stance and extensor burst durations were longer and shorter when the ipsilateral limb was on the slow (Split-slow) and fast (Split-fast) belts, respectively. As expected, contralateral stance phase and extensor burst durations showed an opposite pattern.

B
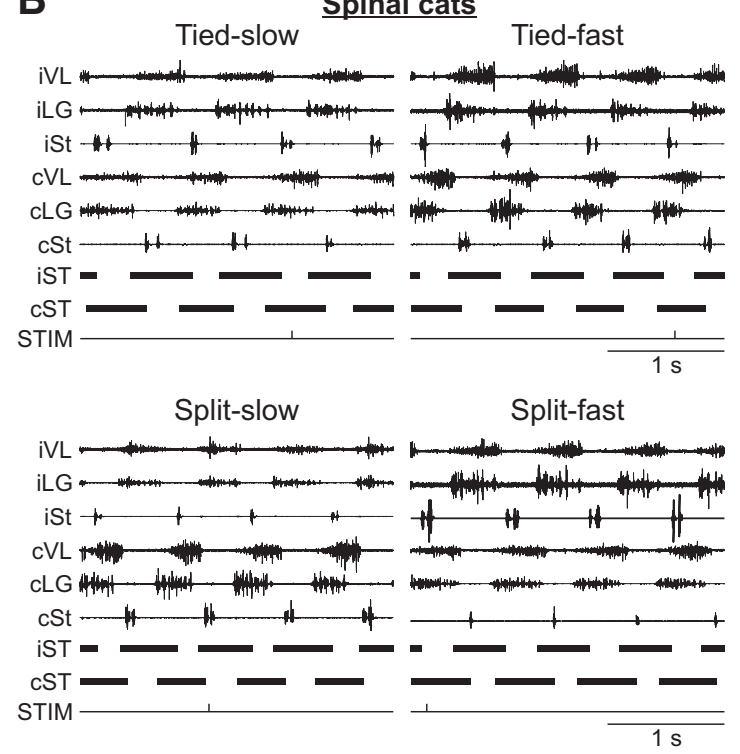

Figure 2. Modulation of the locomotor pattern during tied-belt and split-belt locomotion in intact and spinal cats. The figure shows EMG waveforms from ipsilateral (i) and contralateral (c) hindlimb muscles along with hindlimb stance phases (ST, thick black bars) in the four locomotor conditions in an intact $(\boldsymbol{A})$ and spinal $(\boldsymbol{B})$ cat. The stimulation (STIM) of the ipsilateral SP nerve is shown below the stance phases. 
For pooled data, the locomotor condition significantly affected cycle duration in intact $\left(p=1.05 \times 10^{-8}\right.$, ANOVA $)$ and spinal ( $p=0.02$, ANOVA) cats (Fig. $3 A$ ). As expected, cycle duration was significantly shorter in the Tied-fast condition compared with the Tied-slow condition, whereas during splitbelt locomotion it was intermediate to the tied-belt conditions. We found no significant differences between cycle durations of the ipsilateral and contralateral limbs $(p=0.09$ and $p=0.19$ for intact and spinal cats, respectively, ANOVA), and no significant interactions ( $p=0.10$ and $p=0.35$ for intact and spinal cats, respectively, ANOVA). The locomotor condition also significantly affected stance duration in intact $\left(p=3.61 \times 10^{-8}\right.$, ANOVA) and spinal ( $p=0.0004$, ANOVA) cats (Fig. 3B). Stance durations were shorter bilaterally in the Tied-fast condition compared with the Tied-slow condition. Although we found no significant differences between limbs for intact ( $p=0.19$, ANOVA) and spinal ( $p=0.11$, ANOVA) cats because the split-belt conditions were mirror images, we found significant interactions between condition and $\operatorname{limb}\left(p=2.76 \times 10^{-6}\right.$ and $p=0.00006$ for intact and spinal cats, respectively, ANOVA). The ipsilateral stance phase was significantly longer $(p=0.00008$ and $p=$ 0.0004 for intact and spinal cats, respectively, ANOVA) and shorter $(p=0.0002$ and $p=0.0002$ for intact and spinal cats, respectively, ANOVA) when it was on the slow (Split-slow) and fast (Split-fast) belts, respectively.

The locomotor condition significantly affected the temporal ( $p=0.0003$ and $p=0.00004$ for intact and spinal cats, respectively, ANOVA $)$ and spatial $\left(p=2.23 \times 10^{-10}\right.$ and $p=0.00007$ for intact and spinal cats, respectively, ANOVA) phasing between hindlimbs. Speed did not affect temporal phasing because we observed no difference between tied-belt conditions ( $p=0.95$ and $p=0.11$ for intact and spinal cats, respectively, ANOVA) (Fig. 3C). Having the ipsilateral limb on the slow and fast belts significantly increased and reduced temporal phasing, respectively, compared with one or both tied-belt conditions. One notable difference was that the change in temporal phasing during split-belt locomotion was visibly greater in intact cats compared with spinal cats. Speed also did not affect spatial phasing because we observed no difference between the tied-belt conditions ( $p=$ 0.43 and $p=0.86$ for intact and spinal cats, respectively, ANOVA) (Fig. 3D). Having the ipsilateral limb on the slow and fast belts significantly increased and reduced spatial phasing, respectively, compared with both tied-belt conditions.

The temporal and spatial changes that we observed in the pattern during tied-belt and split-belt locomotion were consistent with previous studies in intact or spinal cats (Forssberg et al., 1980; Halbertsma, 1983; Frigon et al., 2013, 2015, 2017; D’Angelo et al., 2014; Kuczynski et al., 2017). During split-belt locomotion, these changes included temporal and spatial asymmetries between the hindlimbs.

\section{Cutaneous reflex responses in ipsilateral hindlimb muscles}

We compared cutaneous reflexes evoked in ipsilateral and contralateral hindlimb muscles by stimulating the SP nerve during tied-belt and split-belt locomotion in intact and spinal cats. To facilitate comparisons between conditions and muscles, we organized the figures in the same way (Figs. 4, 5, 6, 7, 8). In these figures, panels $A$ and $B$ show responses evoked in intact and spinal cats, respectively, divided into the four conditions: Tiedslow, Tied-fast, Split-slow, and Split-fast. Each subdivision shows averaged waveforms in the 10 bins of the cycle in a window of 65 $\mathrm{ms}$ that starts $5 \mathrm{~ms}$ before the stimulation for a single cat (same cat for all four conditions). To show how evoked responses deviated
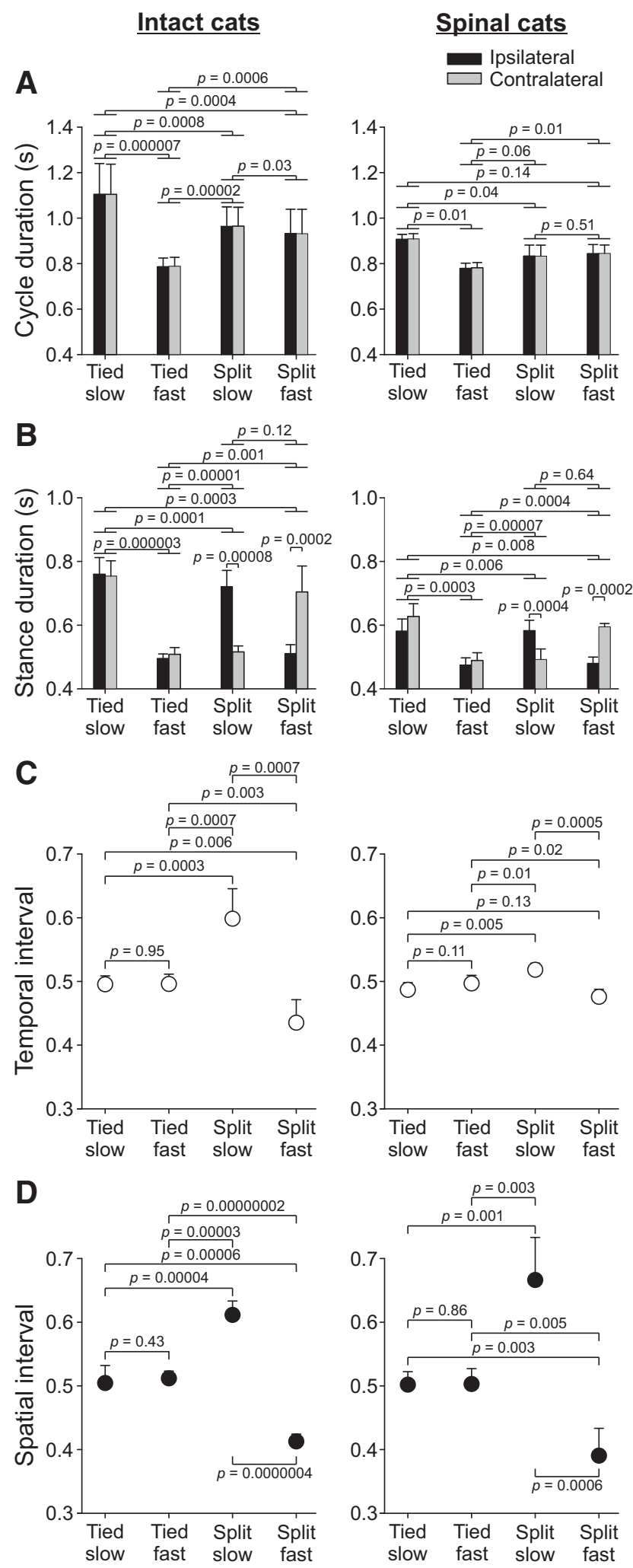

Figure 3. Temporal and spatial parameters during tied-belt and split-belt locomotion for pooled data. Top, cycle $(\boldsymbol{A})$ and stance $(\boldsymbol{B})$ durations of the ipsilateral and contralateral hindlimbs. Bottom, temporal $(\boldsymbol{C})$ and spatial $(\boldsymbol{D})$ intervals between the hindlimbs for pooled data. Each bar/data point is the mean \pm SD of eight trials in five intact cats and six trials in four spinal cats. The $p$-values were obtained with pairwise comparisons. 
A
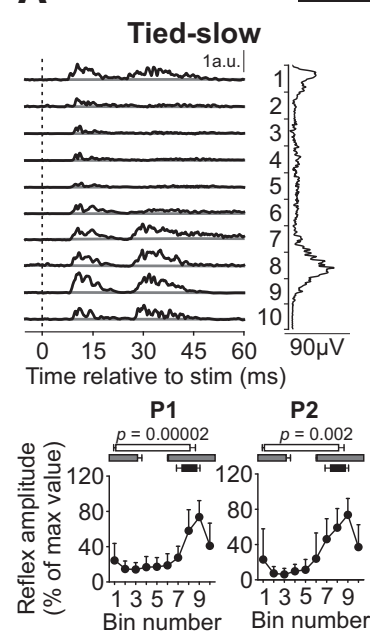

Split-slow

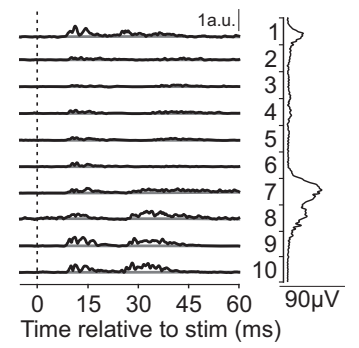

Time relative to stim (ms)

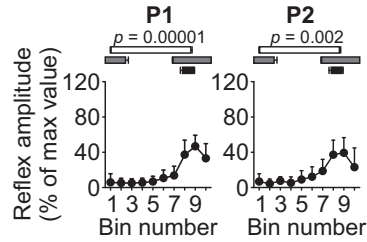

Intact cats

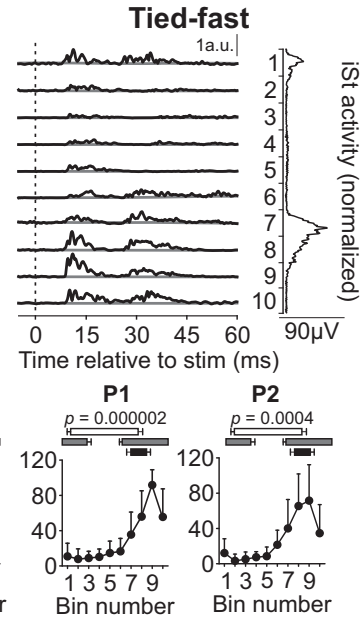

Split-fast

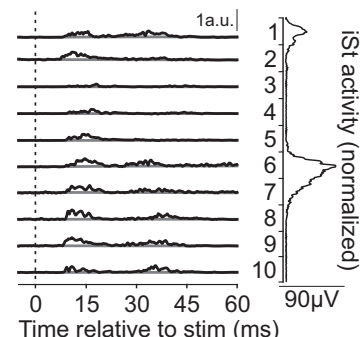

Time relative to stim (ms)

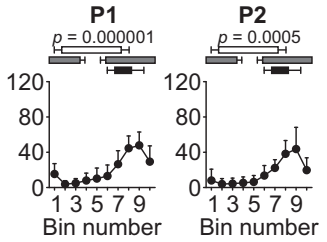

B

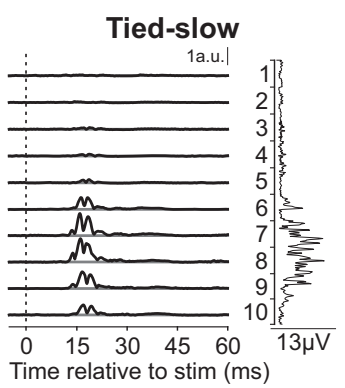

Time relative to stim (ms)

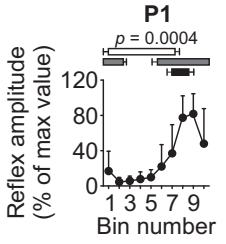

Split-slow
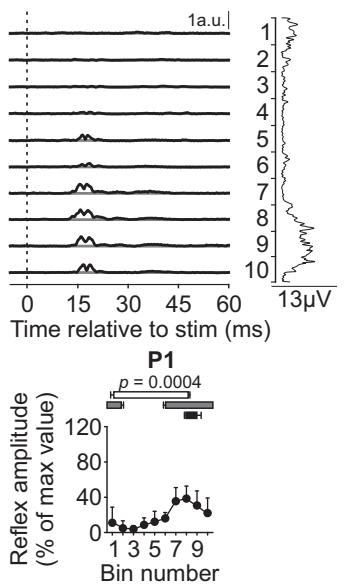

Spinal cats
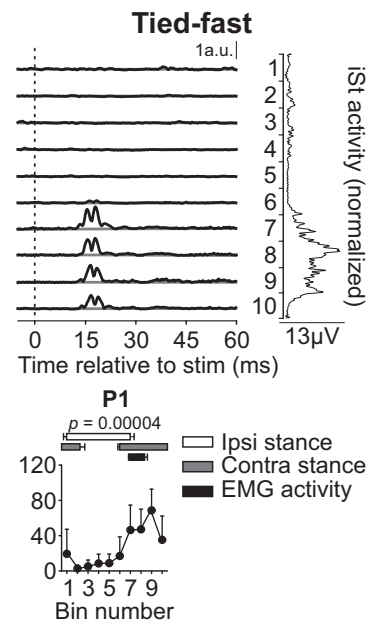

Split-fast
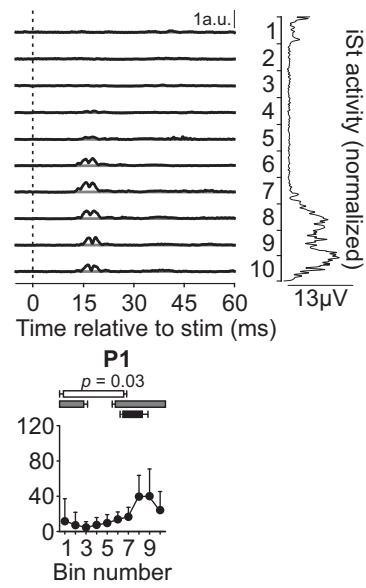

Figure 4. Cutaneous reflexes in the ipsilateral semitendinosus (iSt) during tied-belt and split-belt locomotion. SP nerve stimulation evoked responses in the iSt of intact ( $n=8$ trials in 6 cats; $A$ ) and spinal ( $n=6$ trials in four cats; $\boldsymbol{B}$ ) cats in 4 locomotor conditions. In each condition, we show averaged waveforms in the 10 bins of the cycle with a window of $65 \mathrm{~ms}$ that starts $5 \mathrm{~ms}$ before stimulation in a representative intact and spinal cat. Black traces represent averaged cycles that received a stimulation (i.e., reflex responses, $n=5-27$ stimuli per bin) and gray traces represent averaged cycles without stimulation ( $n=82-266$ cycles). Scale bars, shown in arbitrary units (a.u.), are the same across bins and conditions for a given cat. Aligned vertically to the right is the average rectified EMG trace of the iSt muscle over the cycle normalized to the ipsilateral VL burst onset. Scatter plots represent reflex amplitudes (mean \pm SD) in each bin of the cycle expressed as a percentage of the maximal response found in one of the bins of one of the conditions for pooled data. Horizontal bars above the scatter plots show the stance phases of the ipsilateral (Ipsi) and contralateral (Contra) limbs and the period of EMG activity from 20 to 30 cycles. Error bars indicate mean \pm SD. $p$-values at the top of the scatter plots are the result of the one-factor (phase) repeated-measures ANOVA.

from the normal pattern of EMG, averaged cycles that received a stimulation (black traces) are superimposed on averaged cycles without stimulation (the blEMG). An average rectified EMG trace of the muscle normalized to step cycle onset (onset of the ipsilateral VL or LG) is aligned vertically to the right of the waveforms. The scatter plots below the waveforms show normalized reflex amplitudes of short-latency (P1/N1) and midlatency (P2) responses for pooled data. Ipsilateral and contralateral stance phases, as well as the period of activity of the muscle, are shown above the scatter plots. Because $\mathrm{P} 2$ responses are small or absent in spinal cats, they were not analyzed (LaBella et al., 1992; Duysens et al., 2004; Frigon and Rossignol, 2008a; Hurteau et al., 2017).

We evaluated cutaneous reflexes in the ipsilateral St, a knee flexor and hip extensor that displays a brief period of activity around swing onset and sometimes a second short burst during early stance (Fig. 2). In the present study, stimulating the SP nerve evoked P1 and P2 responses in intact cats that were phase modulated (Fig. 4A). In spinal cats, we observed a similar (not statistically compared) phase-dependent modulation of P1 responses and a reduction or absence of $\mathrm{P} 2$ responses (Fig. $4 B$ ). These results are consistent with previous findings in intact and spinal cats (Forssberg et al., 1977; Forssberg, 1979; Duysens and Loeb, 1980; Pratt et al., 1991; Loeb, 1993; Bretzner and Drew, 2005; Frigon and Rossignol, 2007, 2008a; Frigon et al., 2009; Hurteau et al., 2017, 2018). We found a significant phase-dependent modulation of P1 and P2 (intact cats only) response amplitudes in all conditions for pooled data of intact and spinal cats that peaked in bins 8 or 9 toward the end of the main burst ( $p$-values are indicated on scatter plots, ANOVA), which corresponds to swing onset/early swing. However, we observed notable differences in response amplitudes between tied-belt and split-belt locomotion. Indeed, P1 and/or P2 responses were approximately reduced by half from tied-belt to split-belt locomotion in both the slow and fast limbs in intact and spinal cats.

We next evaluated the modulation of cutaneous reflexes in the ipsilateral VL, a knee extensor that is active throughout most of the stance phase (Fig. 2). In the present study, stimulating the SP nerve in intact cats evoked $\mathrm{N} 1$ responses followed by $\mathrm{P} 2$ responses 
A
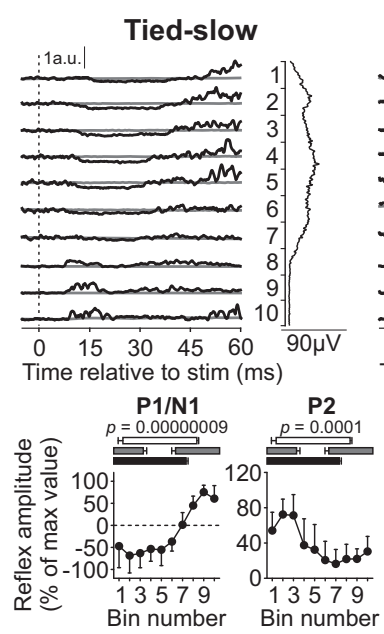

Split-slow
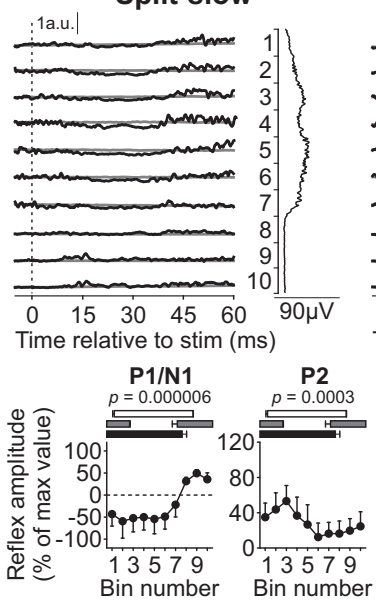

Intact cats
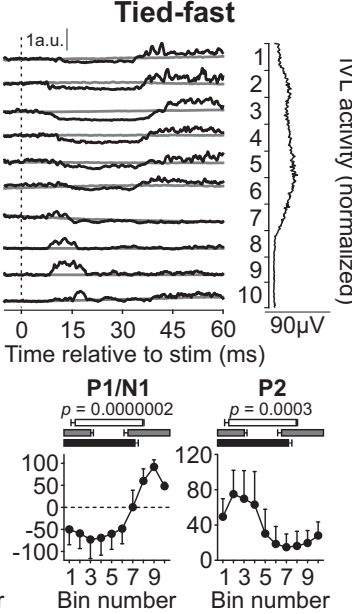

Split-fast

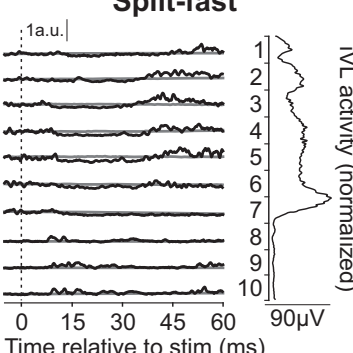

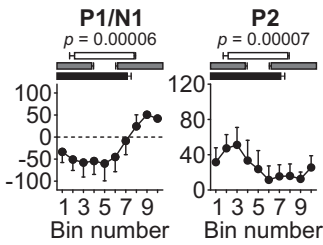

B

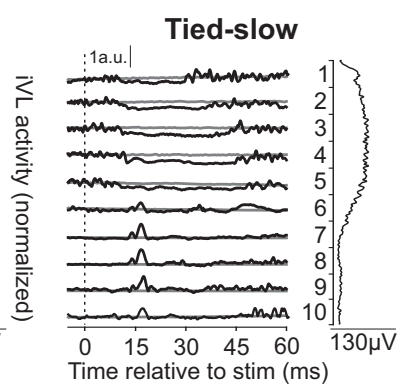

Time relative to stim (ms)

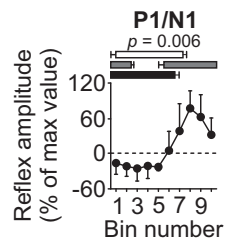

Split-slow

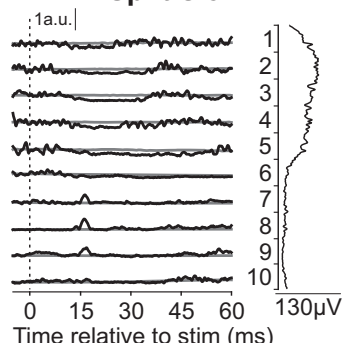

Time relative to stim (ms)

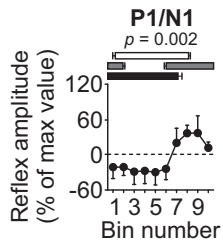

Spinal cats
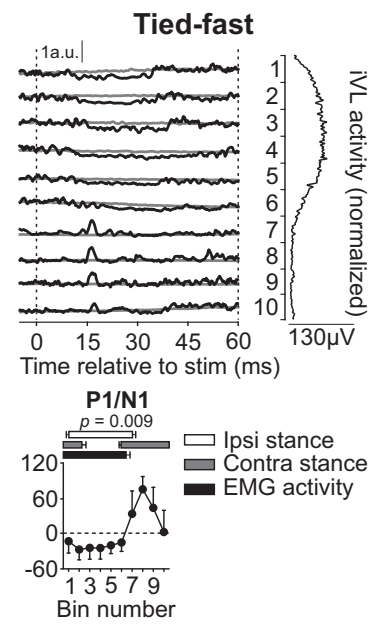

Split-fast

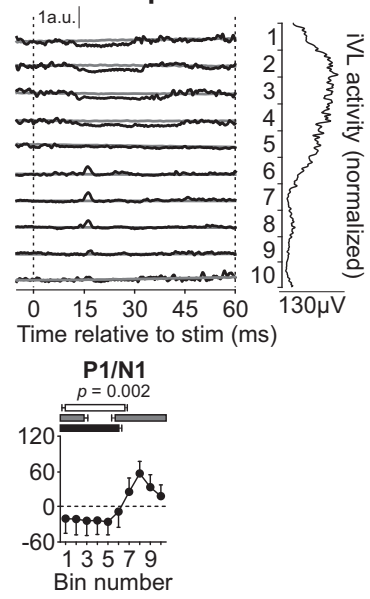

Figure 5. Cutaneous reflexes in the ipsilateral VL (iVL) during tied-belt and split-belt locomotion. SP nerve stimulation evoked responses in the iVL of intact ( $n=7$ trials in 5 cats; $\boldsymbol{A}$ ) and spinal ( $n=5$ trials in 4 cats; $\boldsymbol{B}$ ) cats in 4 locomotor conditions. In each condition, we show averaged waveforms in the 10 bins of the cycle with a window of 65 ms that starts 5 ms before stimulation in a representative intact and spinal cat. Black traces represent averaged cycles that received a stimulation (i.e., reflex responses, $n=5-27$ stimuli per bin) and gray traces represent averaged cycles without stimulation ( $n=82-266$ cycles). Scale bars, shown in arbitrary units (a.u.), are the same across bins and conditions for a given cat. Aligned vertically to the right is the average rectified EMG trace of the iVL muscle over the cycle normalized to its burst onset. Scatter plots represent reflex amplitudes (mean \pm SD) in each bin of the cycle expressed as a percentage of the maximal response found in one of the bins of one of the conditions for pooled data. Horizontal bars above the scatter plots show the stance phases of the ipsilateral (Ipsi) and contralateral (Contra) limbs and the period of EMG activity from 20 to 30 cycles. Error bars indicate mean \pm SD. $p$-values at the top of the scatter plots are the result of the one-factor (phase) repeated-measures ANOVA.

when the $\mathrm{VL}$ was active and $\mathrm{P} 1$ responses when the muscle was inactive (Fig. 5A). In spinal cats, we observed similar (not statistically compared) $\mathrm{N} 1$ and $\mathrm{P} 1$ responses and a reduction or absence of $\mathrm{P} 2$ responses (Fig. 5B). These results are consistent with previous findings in intact and spinal cats (Duysens and Loeb, 1980; Abraham et al., 1985; Pratt et al., 1991; Loeb, 1993; Frigon and Rossignol, 2008a; Hurteau et al., 2017, 2018). We found a significant phase-dependent modulation of N1/P1 and P2 (intact cats only) response amplitudes in all conditions for pooled data of intact and spinal cats ( $p$-values are indicated on scatter plots, ANOVA). The P1 responses peaked in bin 9 and bin 8 in intact and spinal cats, respectively, when the muscle was inactive, which corresponds to swing onset/early swing, whereas $\mathrm{P} 2$ responses of intact cats peaked in bins 2 or 3 at the start of the VL's activity at stance onset/early stance. Again, we observed notable differences in response amplitudes between tied-belt and split-belt locomotion in both groups. In intact cats, we observed less negative N1 responses during split-belt locomotion and smaller P1 and P2 responses compared with tied-belt locomotion. In spinal cats, although N1 responses were similar (not statistically compared) during tied-belt and split-belt locomotion, we observed a reduction in P1 responses.

Next, we evaluated the modulation of cutaneous reflexes in the ipsilateral LG, an ankle extensor and knee flexor that, like VL, is active throughout most of the stance phase (Fig. 2). In the present study, stimulating the SP nerve in intact cats evoked N1 responses followed by $\mathrm{P} 2$ responses when the LG was active, as well as P1 and P2 responses toward the end of the LG's activity and when inactive (Fig. 6A). In spinal cats, we did not observe N1 responses when the LG muscle was active. Our results are consistent with Frigon and Rossignol (2008a), who described an absence or reduction of N1 responses in ipsilateral extensors, in particular the gastrocnemii, by comparing responses in the same cats before and after spinal transection. Instead, we observed P1 responses that peaked toward the end of the LG's activity and when inactive (Fig. 6B). These results are consistent with previous findings in intact and spinal cats (Duysens and Loeb, 1980; Abraham et al., 1985; Loeb, 1993; Frigon and Rossignol, 2008a; 
A
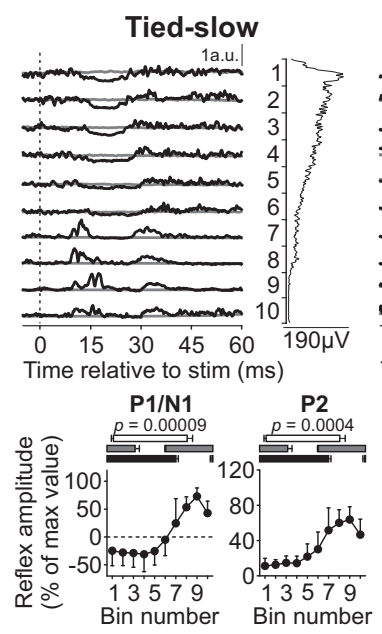

Split-slow
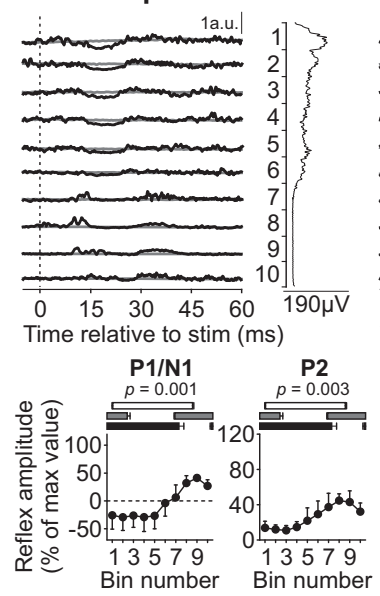

Intact cats
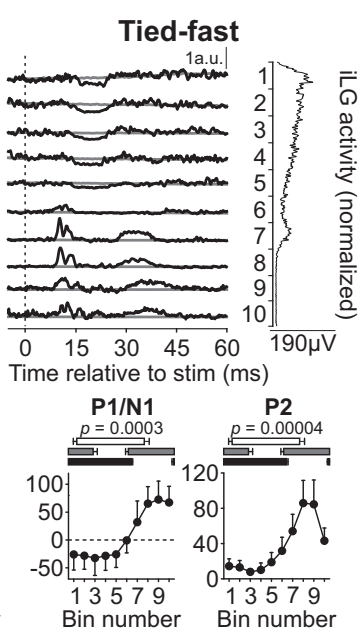

Split-fast
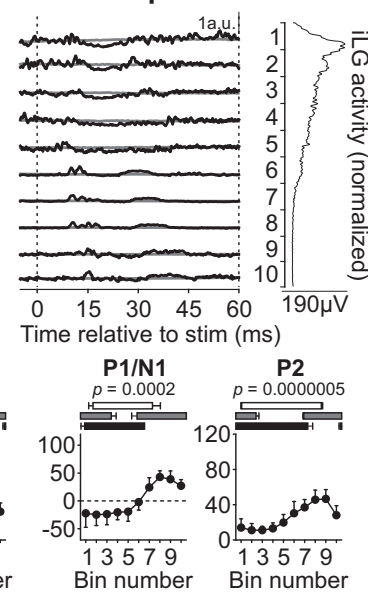

B
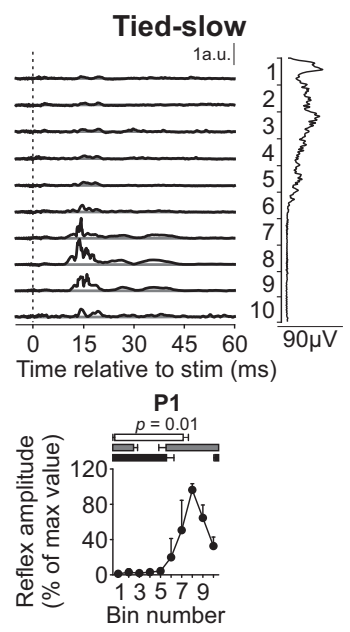

Split-slow
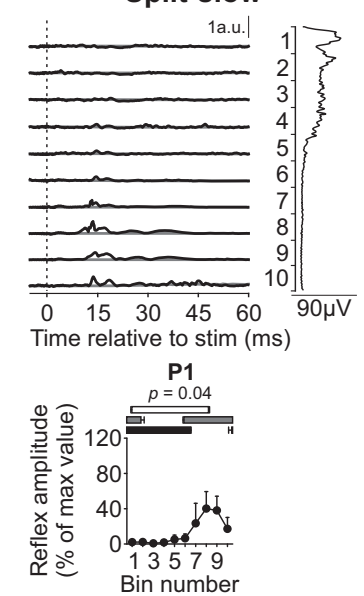

Spinal cats
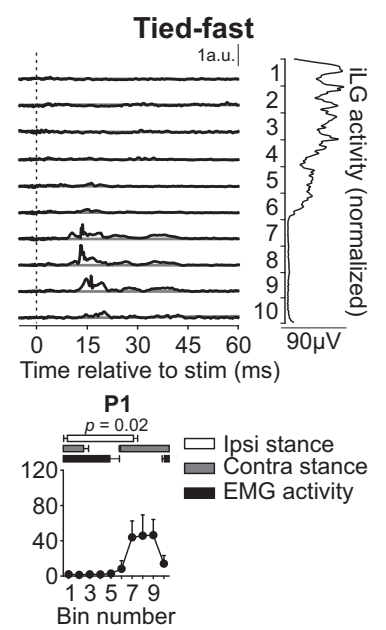

Split-fast
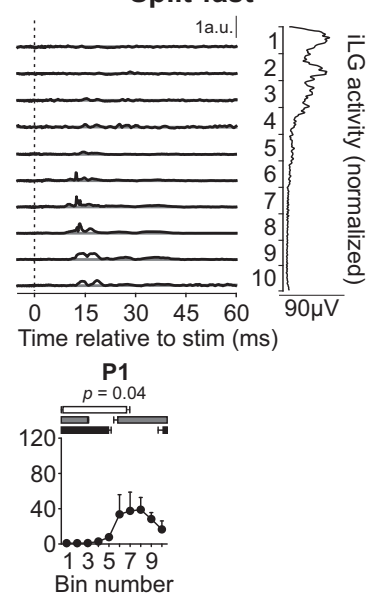

Figure 6. Cutaneous reflexes in the ipsilateral LG (iLG) during tied-belt and split-belt locomotion. SP nerve stimulation evoked responses in the iLG of intact ( $n=6$ trials in 4 cats; $A$ ) and spinal $(n=4$ trials in 3 cats; $\boldsymbol{B})$ cats in 4 locomotor conditions. In each condition, we show averaged waveforms in the 10 bins of the cycle with a window of $65 \mathrm{~ms}$ that starts $5 \mathrm{~ms}$ before stimulation in a representative intact and spinal cat. Black traces represent averaged cycles that received a stimulation (i.e., reflex responses, $n=4-21$ stimuli per bin) and gray traces represent averaged cycles without stimulation ( $n=83-180$ cycles). Scale bars, shown in arbitrary units (a.u.), are the same across bins and conditions for a given cat. Aligned vertically to the right is the average rectified EMG trace of the iLG muscle over the cycle normalized to the ipsilateral VL burst onset. Scatter plots represent reflex amplitudes (mean \pm SD) in each bin of the cycle expressed as a percentage of the maximal response found in one of the bins of one of the conditions for pooled data. Horizontal bars above the scatter plots show the stance phases of the ipsilateral (Ipsi) and contralateral (Contra) limbs and the period of EMG activity from 20 to 30 cycles. Error bars indicate mean \pm SD. $p$-values at the top of the scatter plots are the result of the one-factor (phase) repeated-measures ANOVA.

Frigon et al., 2009; Hurteau et al., 2017; Hurteau et al., 2018). We found a significant phase-dependent modulation of N1/P1 and P2 (intact cats only) response amplitudes in all conditions for pooled data of intact and spinal cats ( $p$ values are indicated on scatter plots, ANOVA). The P1 responses peaked in bins 8 or 9 , which correspond to swing onset/early swing, in intact and spinal cats when the muscle was inactive, as did P2 responses of intact cats. Once again, we observed notable differences in response amplitudes between tied-belt and split-belt locomotion in both groups. In intact cats, P1 and P2 responses were smaller during split-belt locomotion compared with tied-belt locomotion. In spinal cats, P1 responses were also smaller during split-belt locomotion, particularly compared with the Tied-slow condition.

In summary, although cutaneous reflex responses in ipsilateral muscles (St, VL, and LG) maintained a similar (not statistically compared) pattern of phase modulation during tied-belt and split-belt locomotion in intact and spinal cats, response amplitudes were smaller in both the slow and fast limbs during splitbelt locomotion.
Cutaneous reflex responses in contralateral hindlimb muscles Although responses to mechanical or electrical stimuli of the foot dorsum in ipsilateral limb muscles serve to move or lift the limb away from the stimulus, responses in contralateral limb muscles mainly reinforce weight support (Forssberg et al., 1977; Prochazka et al., 1978; Forssberg, 1979; Duysens and Loeb, 1980; Buford and Smith, 1993). Here, we investigated cutaneous reflexes in the contralateral VL and LG during tied-belt and splitbelt locomotion in intact and spinal cats. However, because we adjusted stimulation intensity just above the threshold to evoke responses in the ipsilateral St to avoid perturbing the pattern, crossed responses were not present with all nerve stimulations.

In intact and spinal cats, stimulating the SP nerve evoked P1 responses in the contralateral VL when the muscle was active, as shown recently (Hurteau et al., 2017, 2018). We found a significant phase-dependent modulation of $\mathrm{P} 1$ response amplitudes in all conditions for pooled data of intact (Fig. 7A) and spinal (Fig. $7 B$ ) cats ( $p$-values are indicated on scatter plots, ANOVA). In intact cats, we observed a U-shaped phase-dependent modula- 
A

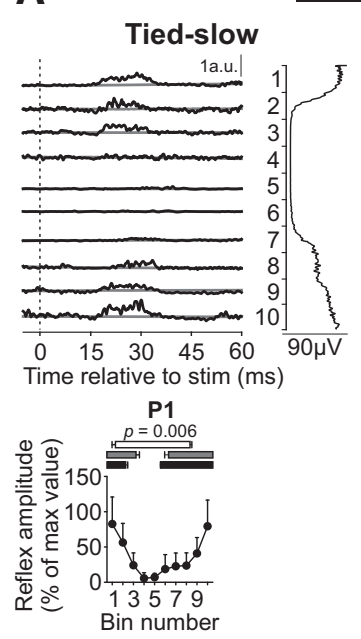

Split-slow
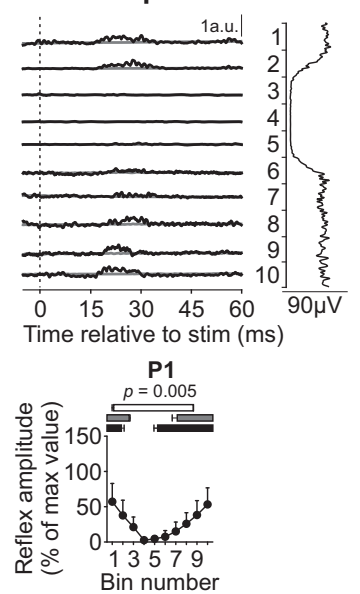

Intact cats
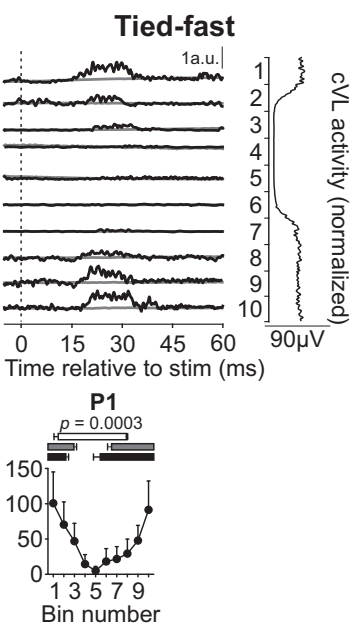

Split-fast

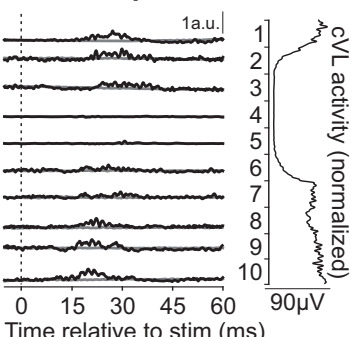

Time relative to stim (ms)

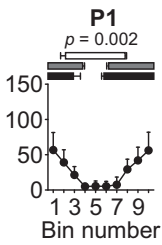

B

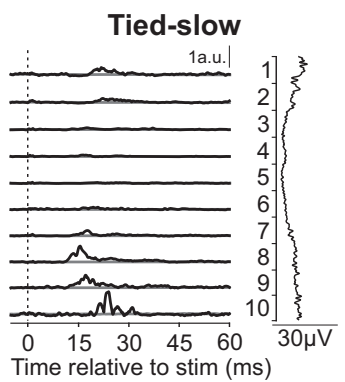

Time relative to stim (ms) Time relative to stim $(\mathrm{ms})$

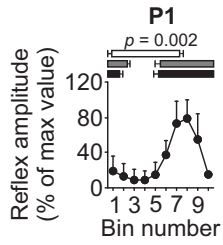

Split-slow
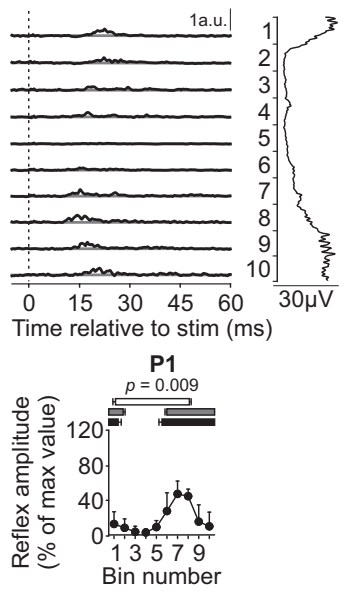

Tied-fast

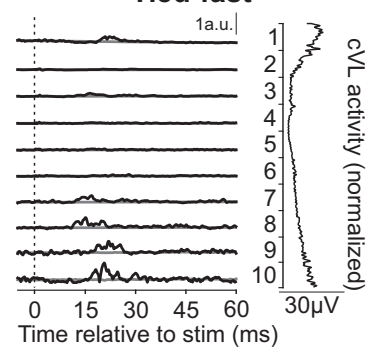

P1

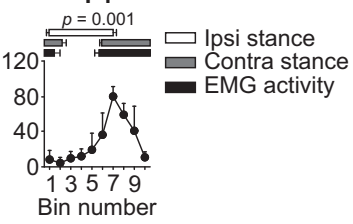

Split-fast
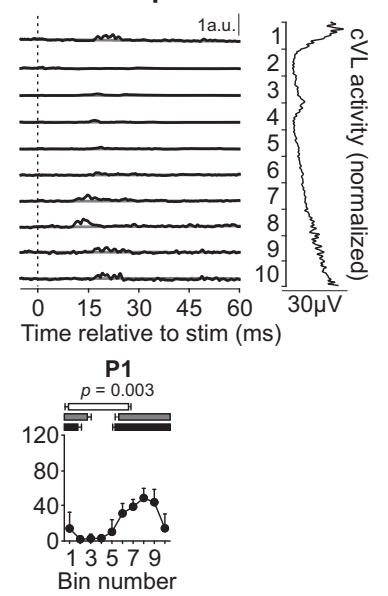

Figure 7. Cutaneous reflexes in the contralateral VL ( $\mathrm{CVL}$ ) during tied-belt and split-belt locomotion. SP nerve stimulation evoked responses in the cVL of intact ( $n=4$ trials in 4 cats; $A$ ) and spinal ( $n=5$ trials in 3 cats; $\boldsymbol{B}$ ) cats in 4 locomotor conditions. In each condition, we show averaged waveforms in the 10 bins of the cycle with a window of $65 \mathrm{~ms}$ that starts $5 \mathrm{~ms}$ before stimulation in a representative intact and spinal cat. Black traces represent averaged cycles that received a stimulation (i.e., reflex responses, $n=4-19$ stimuli per bin) and gray traces represent averaged cycles without stimulation ( $n=82-242$ cycles). Scale bars, shown in arbitrary units (a.u.), are the same across bins and conditions for a given cat. Aligned vertically to the right is the average rectified EMG trace of the CVL muscle over the cycle normalized to the ipsilateral VL burst onset. Scatter plots represent reflex amplitudes (mean \pm SD) in each bin of the cycle expressed as a percentage of the maximal response found in one of the bins of one of the conditions for pooled data. Horizontal bars above the scatter plots show the stance phases of the ipsilateral (Ipsi) and contralateral (Contra) limbs and the period of EMG activity from 20 to 30 cycles. Error bars indicate mean \pm SD. $p$-values at the top of the scatter plots are the result of the one-factor (phase) repeated-measures ANOVA.

tion, with the largest responses found at the end of the contralateral VL burst/late stance, when the ipsilateral limb was in mid- to late swing (bins 10 and 1). In spinal cats, responses peaked in the early to middle part of the contralateral VL burst, when the ipsilateral limb was in late stance or early swing (bins 7 and 8). In both intact and spinal cats, peak P1 response amplitudes during split-belt locomotion were approximately half those observed during tied-belt locomotion.

In intact cats (Fig. $8 A$ ), stimulating the SP nerve evoked P2 responses in the contralateral LG that were sometimes preceded by N1 responses (Frigon and Rossignol, 2008b), whereas in spinal cats (Fig. $8 B$ ), we only observed P1 responses. The lack of N1 responses in spinal cats could explain the shorter latency of excitatory responses. To facilitate comparisons between intact and spinal cats, we only analyzed excitatory responses (P2 and P1 in intact and spinal cats, respectively). Due to the small number of nerves that evoked responses in the crossed LG in intact cats $(n=2)$, we did not find a significant phase- dependent modulation of $\mathrm{P} 2$ responses, whereas in spinal cats $(n=3), \mathrm{P} 1$ responses were significantly modulated by phase in the Tied-slow and Split-fast conditions ( $p$-values are indicated on scatter plots, ANOVA). In intact cats, we observed the largest responses toward the end of the contralateral LG burst, when the ipsilateral limb was in mid-swing (bin 10). In spinal cats, responses peaked in the middle part of the contralateral LG burst, when the ipsilateral limb was in late stance or early swing (bins 7 and 8). In both intact and spinal cats, peak P2 or P1 response amplitudes during split-belt locomotion were approximately half those observed during tied-belt locomotion.

In summary, cutaneous reflex responses in contralateral extensors (VL and LG) maintained a similar (not statistically compared) pattern of phase modulation during tied-belt and split-belt locomotion in intact and spinal cats. However, in both groups, response amplitudes were smaller in both the slow and fast limbs during split-belt locomotion. 
A
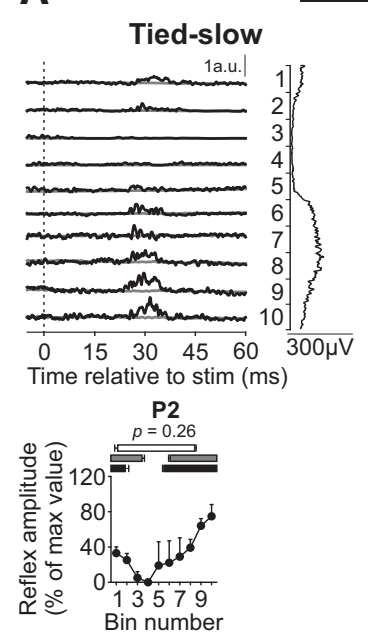

Split-slow
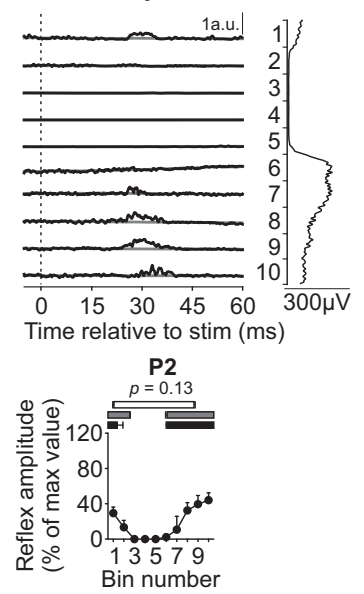

Intact cats
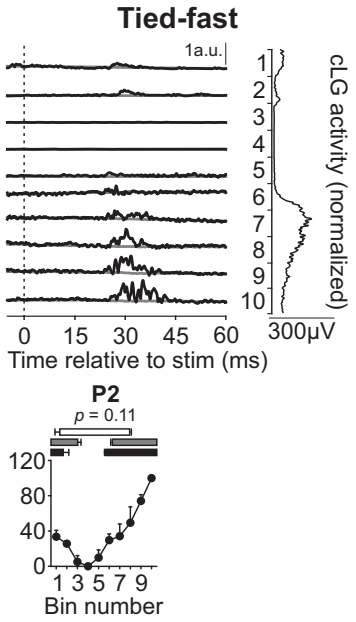

Split-fast

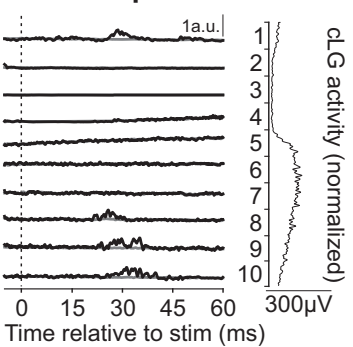

P2

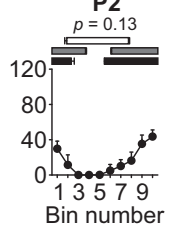

B
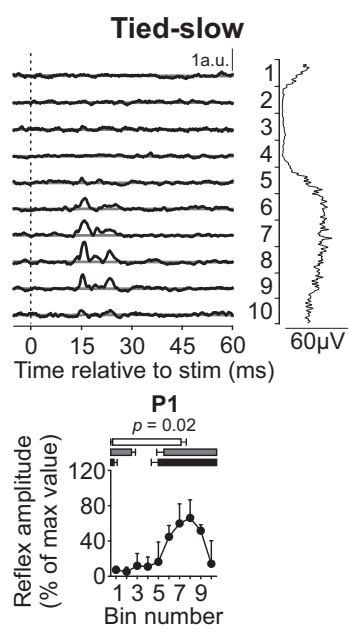

Split-slow
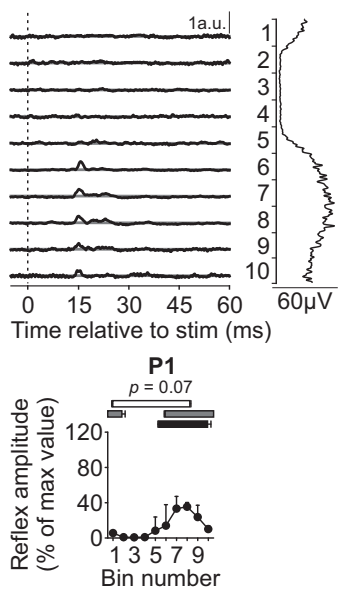

Tied-fast
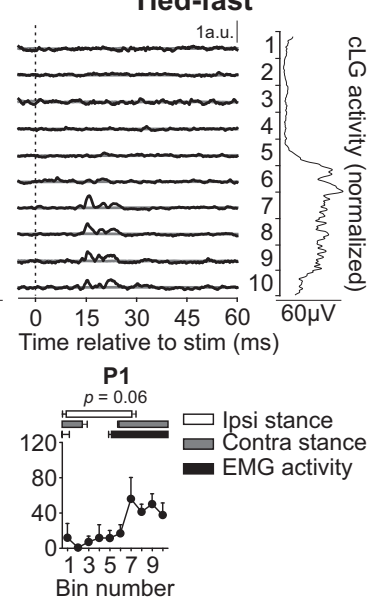

Split-fast
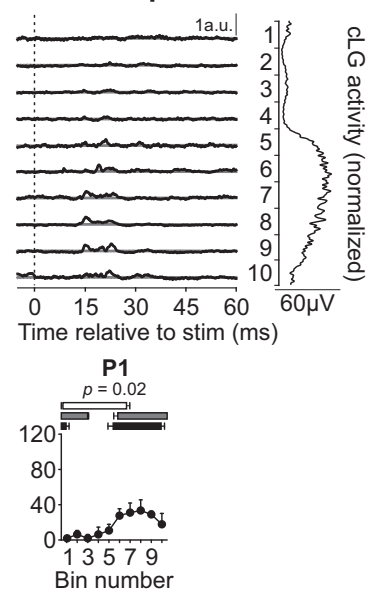

Figure 8. Cutaneous reflexes in the contralateral LG (CLG) during tied-belt and split-belt locomotion. SP nerve stimulation evoked responses in the $\mathrm{LL} G$ of intact $(n=2$ trials in 2 cats; $A$ ) and spinal $(n=3$ trials in 2 cats; $\boldsymbol{B})$ cats in 4 locomotor conditions. In each condition, we show averaged waveforms in the 10 bins of the cycle with a window of $65 \mathrm{~ms}$ that starts $5 \mathrm{~ms}$ before stimulation in a representative intact and spinal cat. Black traces represent averaged cycles that received a stimulation (i.e., reflex responses, $n=5-27$ stimuli per bin) and gray traces represent averaged cycles without stimulation ( $n=68-266$ cycles). Scale bars, shown in arbitrary units (a.u.), are the same across bins and conditions for a given cat. Aligned vertically to the right is the average rectified EMG trace of the cLG muscle over the cycle normalized to the ipsilateral VL burst onset. Scatter plots represent reflex amplitudes (mean \pm SD) in each bin of the cycle expressed as a percentage of the maximal response found in one of the bins of one of the conditions for pooled data. Horizontal bars above the scatter plots show the stance phases of the ipsilateral (Ipsi) and contralateral (Contra) limbs and the period of EMG activity from 20 to 30 cycles. Error bars indicate mean \pm SD. $p$-values at the top of the scatter plots are the result of the one-factor (phase) repeated-measures ANOVA.

\section{Asymmetric stepping reduces cutaneous reflex amplitude independently of speed}

To compare reflex responses evoked in the different conditions, we measured a modulation index for each condition by subtracting the smallest response from the largest response observed in the 10 bins (Hurteau et al., 2017). For short-latency responses in $\mathrm{VL}$ and LG, because both $\mathrm{N} 1$ and $\mathrm{P} 1$ responses were present, the modulation indexes could exceed $100 \%$. The modulation indexes for all muscles, ipsilateral and contralateral, were strikingly similar (not statistically compared) across conditions. In intact cats, we observed the largest modulation indexes for P1/N1 and P2 responses in the Tied-fast condition followed by the Tied-slow condition and the two split-belt conditions (Fig. 9A). For the majority of responses in all muscles, we found a significant increase in the modulation indexes from the Tied-slow to the Tied-fast conditions. Conversely, we found significantly smaller modulation indexes for the majority of responses in all muscles in the two split-belt conditions compared with the tied-belt conditions, with no significant differences between split-belt condi- tions for all responses. Note that we observed only one significant change in P2 responses of the contralateral LG because of the small number of evoked responses $(n=2$ from eight nerves stimulated). In spinal cats, we observed the largest modulation indexes for P1/N1 responses in the Tied-slow condition followed by the Tied-fast condition and the two split-belt conditions (Fig. $9 B$ ). We found a significant decrease in the modulation indexes from the Tied-slow to the Tied-fast conditions for all muscles with the exception of the ipsilateral VL ( $p=0.09$, ANOVA). We found significantly smaller modulation indexes in the two splitbelt conditions of all muscles compared with one or both tiedbelt conditions.

In summary, split-belt locomotion reduced cutaneous reflex modulation compared with tied-belt locomotion in both intact and spinal cats. Although we observed significant differences in cutaneous reflex modulation between the two tied-belt speeds (i.e., a speed-dependent effect), we found no significant differences between the two split-belt conditions even though in one condition evoked responses were in the slow limb and in the 


\section{A Intact cats}

P1/N1 Ipsilateral St

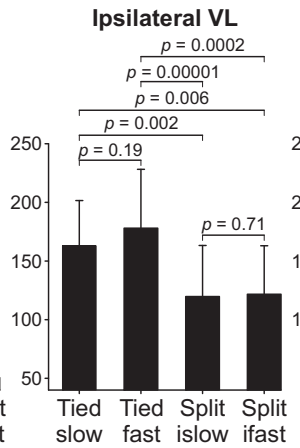

Ipsilateral LG

Contralateral VL
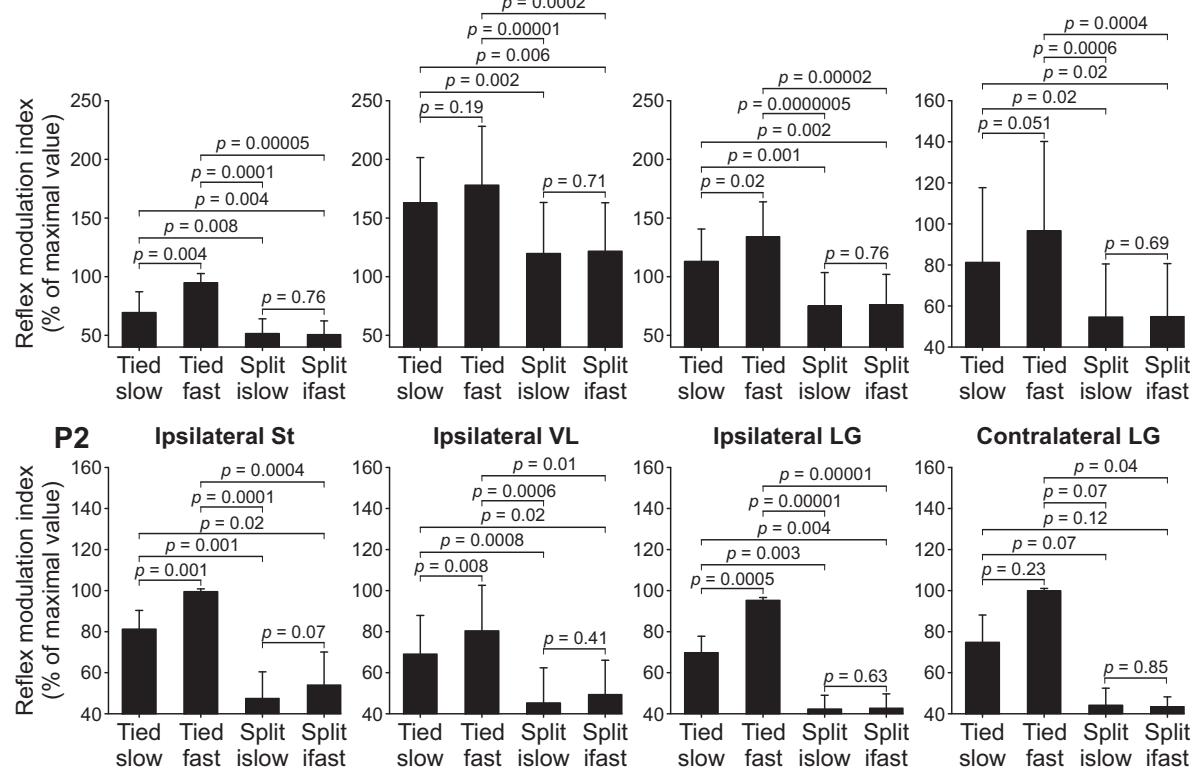

\section{B Spinal cats

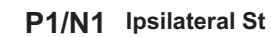

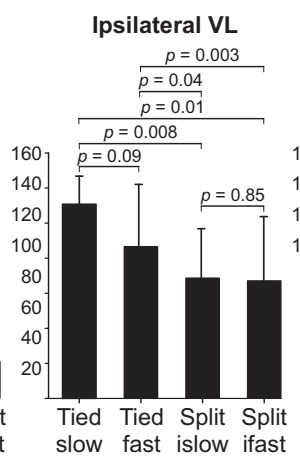

Ipsilateral LG

Contralateral VL

Contralateral LG
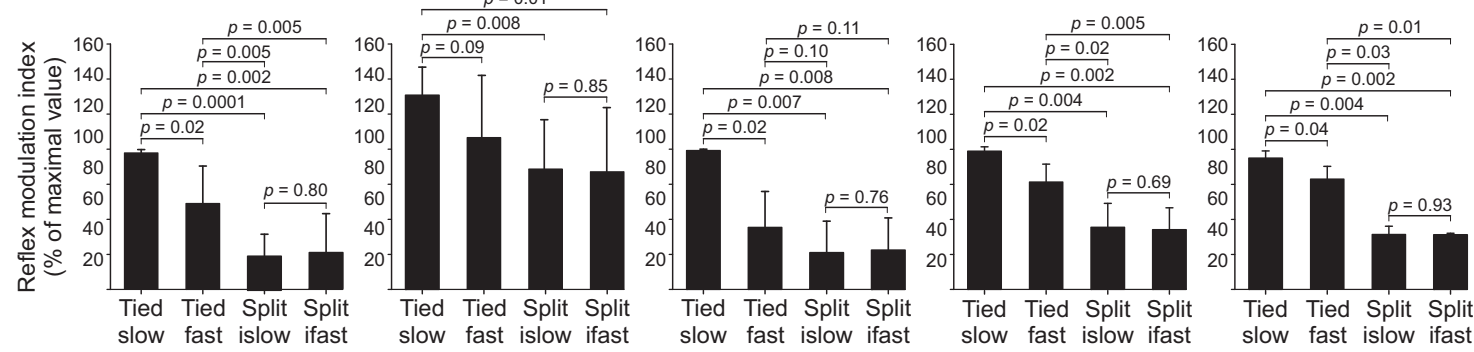

Figure 9. Cutaneous reflex modulation across locomotor conditions for pooled data. The figure shows the modulation indexes for P1/N1 and/or P2 responses for all muscles obtained in each condition for intact $(\boldsymbol{A})$ and spinal $(\boldsymbol{B})$ cats. Each bar represents the mean \pm SD of pooled data (i.e., nerves stimulated, see legends of Figs. 3, 4, 5, 6 , and 7 for the number of trials and cats). $p$-values were obtained with pairwise comparisons.

other condition they were in the fast limb. This indicates a reflex modulation independent of speed during split-belt locomotion.

\section{Cutaneous reflex modulation correlates with left-right symmetry}

We recently showed that cutaneous reflex modulation in spinal cats as a function of speed correlated with spatial left-right symmetry, as opposed to temporal symmetry (Hurteau et al., 2017). Similar to that study, we measured the temporal (Fig. 10A) and spatial (Fig. 10B) phasing indexes, an indication of how the locomotor pattern deviates from perfect left-right symmetry (a zero value) on a step-by-step basis. Locomotor condition significantly affected the temporal index of intact cats $(p=0.001$, ANOVA), but not of spinal cats ( $p=0.21$, ANOVA). As stated earlier, the change in the temporal phasing between the hindlimbs induced by split-belt locomotion was visibly greater in intact cats compared with spinal cats, which could be due to a supraspinal/volitional effect (see Discussion). In intact cats, an increase in speed during tied-belt locomotion significantly reduced the temporal index ( $p=0.01$, ANOVA), indicating a more symmetric pattern. In contrast, both split-belt conditions significantly increased the temporal index compared with both tied-belt conditions, consistent with a more asymmetric temporal pattern. In both intact and spinal cats, locomotor condition significantly affected the spatial index $(p=0.000007$ and $p=0.0006$ for intact and spinal cats, respectively, ANOVA). In intact cats, an increase in speed during tied-belt locomotion significantly reduced the spatial index ( $p=$ 0.00009 , ANOVA), indicating a more symmetric pattern, whereas we observed no such change in spinal cats $(p=0.19$, ANOVA). Conversely, both split-belt conditions significantly increased the spatial index compared with both tied-belt conditions, consistent with a more asymmetric spatial pattern.

To determine whether the modulation of reflexes in the different conditions correlated with changes in temporal and spatial symmetry, we measured Pearson's correlation coefficient $(r)$ between the modulation index of P1 responses of the ipsilateral St and the temporal and spatial indexes. We selected P1 responses of the ipsilateral St because they were present in all intact and spinal cats. The modulation index of the ipsilateral St correlated negatively and significantly with the temporal index of intact cats $(r=$ $-0.643, p=0.0007$, bivariate correlation), but not in spinal cats $(r=-0.361, p=0.083$, bivariate correlation). Conversely, the 


\section{Intact cats}

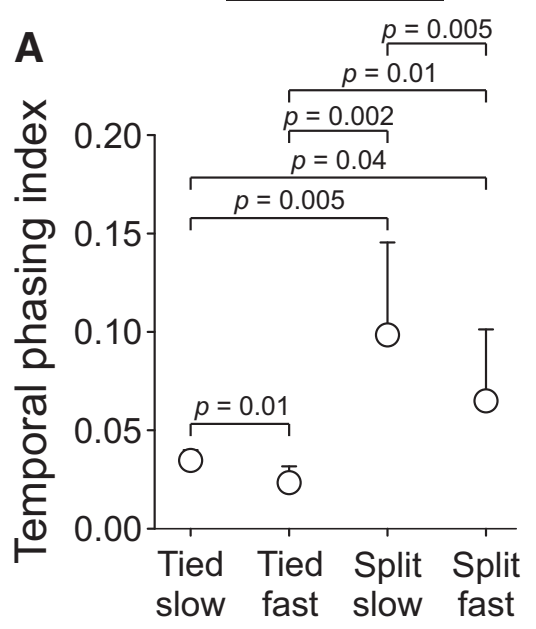

B

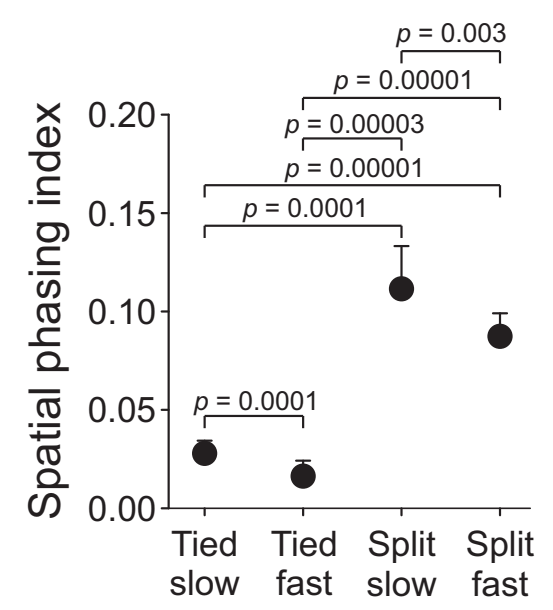

Spinal cats

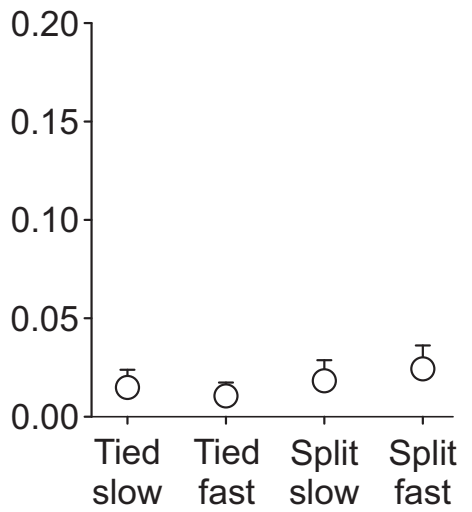

Figure 10. Temporal and spatial symmetry of the locomotor pattern across conditions for pooled data. The figure shows temporal $(\boldsymbol{A})$ and spatial $(\boldsymbol{B})$ phasing indexes for pooled data ( $n=8$ trials in 5 intact cats and $n=6$ trials in 4 spinal cats). Each data point is the mean \pm SD of pooled data. $p$-values were obtained with pairwise comparisons. Note that pairwise comparisons were not performed for the temporal phasing index of spinal cats because there was no significant main effect of the conditions (repeated-measures ANOVA).

modulation index of the ipsilateral St correlated negatively and significantly with the spatial index in both intact $(r=-0.723$, $p=2.93 \times 10^{-6}$, bivariate correlation $)$ and spinal $(r=-0.602$, $p=0.002$, bivariate correlation) cats. These results indicate that, as spatial asymmetry increases, cutaneous reflex modulation decreases.

\section{Discussion}

We characterized cutaneous reflexes in three ipsilateral and two contralateral hindlimb muscles of intact and spinal cats during tied-belt locomotion at two speeds and during split-belt locomotion at one left-right speed difference with the ipsilateral limb stepping on the slow and fast belts. We showed similar phasedependent reflex modulation in all muscles during tied-belt and split-belt locomotion. However, in all muscles, split-belt locomotion reduced reflex modulation compared with tied-belt locomotion. Moreover, although speed significantly affected reflex modulation during tied-belt locomotion, with a differential change in intact and spinal cats, we observed no differences between the slow and fast limbs during splitbelt locomotion. Our results indicate that a signal related to left-right symmetry reduces cutaneous reflex modulation via a spinal mechanism. In the following sections, we consider the functional role of this spinal-mediated task-dependent modulation and potential mechanisms involved.

\section{Functional considerations}

The main questions are as follows: why is cutaneous reflex modulation smaller during split-belt locomotion and what function does this serve? To answer these questions, we must consider how splitbelt locomotion alters the pattern. Specifically, it creates temporal and spatial asymmetries between left and right sides, or slow and fast limbs, simulating some aspects of stepping along a curved path, such as a faster speed for the outer leg that must travel a greater distance in the same amount of time as the inner leg (Courtine and Schieppati, 2003a,b). Stepping on a split-belt treadmill also simulates a limping gait (Duysens et al., 2004, 2012; McFadyen et al., 2009; Hoogkamer et al., 2015), particularly in cats, in which the pattern does not adapt to prolonged exposure (Kuczynski et al., 2017), contrary to humans (Prokop et al., 1995; Reisman et al., 2005). We consider the limping gait induced by split-belt locomotion an unstable form of locomotion, as observed in some pathologies (Harris-Love et al., 2001; Duysens et al., 2012; Handžić and Reed, 2015). Here, we define stability as the body's resistance to disruption of dynamic balance (equilibrium). In other words, during limping, as occurs with split-belt locomotion, the body is relatively less resistant to disruptions of its dynamic balance compared with symmetrical gaits, such as tied-belt locomotion. We propose that reducing cutaneous reflexes during split-belt locomotion decreases the risk of destabilizing the pattern, thus maximizing dynamic balance when gait is unstable or detected as such.

However, as a trade-off, reduced cutaneous reflexes would also mean a diminished capacity in responding to obstacles. To compensate, walking in an environment with a greater perceived risk of falling or threat to postural stability increases the gain of cutaneous reflexes (Haridas et al., 2005, 2006). In other words, when the system anticipates disruptions to stability, it increases the effect of cutaneous feedback when perturbed, whereas when already destabilized, such as limping during split-belt locomotion, it reduces cutaneous reflexes to avoid further destabilizing the pattern. Precision walking on a narrow beam also reduces the amplitude of another type of reflex, the soleus H-reflex, by $\sim 40 \%$ compared with treadmill locomotion at matched speeds in healthy human subjects (Llewellyn et al., 1990). Some patholo- 
gies that induce spasticity, such as spinal cord injury and multiple sclerosis, in which we assume gait is unstable, also reduced reflex modulation ( $\mathrm{H}-$, stretch, and cutaneous reflexes) in humans (Yang et al., 1991; Jones and Yang, 1994; Sinkjaer et al., 1995, 1996). These studies concluded that impaired interactions between afferent inputs from the legs and central mechanisms contributed to locomotor deficits. However, they did not investigate symmetry between the legs, which could be a main factor driving the modulation.

\section{Reflex modulation correlates with left-right symmetry}

We recently showed that speed modulated cutaneous reflexes nonlinearly in spinal cats, with the largest amplitudes observed at intermediate speeds of 0.4 and $0.6 \mathrm{~m} / \mathrm{s}$ and the smallest responses observed at the slowest and fastest speeds of 0.2 and 0.8 $\mathrm{m} / \mathrm{s}$, respectively (Hurteau et al., 2017). In the present study, cutaneous reflex modulation increased from 0.4 to $0.7 \mathrm{~m} / \mathrm{s}$ in intact cats, whereas it decreased from 0.4 to $0.6 \mathrm{~m} / \mathrm{s}$ in spinal cats (Fig. 9). Could this be a difference in reflex modulation as a function of locomotor speed between intact and spinal cats? Although we cannot completely exclude this possibility, we think that speed-dependent changes in left-right symmetry instead explain this differential modulation. Indeed, the pattern of intact cats became more symmetric, both temporally and spatially, with increasing speed during tied-belt locomotion, whereas we observed a small nonsignificant decrease in spatial symmetry in spinal cats with no temporal changes (Fig. 10). The step-by-step consistency of left-right symmetry increases with increasing speed in intact cats, at least up to $1.0 \mathrm{~m} / \mathrm{s}$ (Frigon et al., 2014), and in spinal cats from 0.1 to $0.4 \mathrm{~m} / \mathrm{s}$ (Dambreville et al., 2015). However, in spinal cats, the step-bystep consistency of left-right symmetry starts breaking down at $\sim 0.6 \mathrm{~m} / \mathrm{s}$ and we observed a loose coupling between hindlimbs at faster speeds (Frigon et al., 2017). A notable difference between intact and spinal cats is activation of hip flexors before knee flexors at the stance-to-swing transition, which is thought to contribute to paw drag during early swing (Jiang and Drew, 1996; Rossignol and Frigon, 2011). As speed increases, impaired phase transitions produce greater locomotor instabilities in spinal cats. Here, we manipulated left-right symmetry with split-belt locomotion to simulate limping. The modulation of $\mathrm{P} 1$ responses in the ipsilateral St correlated with spatial and temporal asymmetry in intact cats and with spatial asymmetry in spinal cats. Therefore, overall, reflex modulation correlated more with spatial asymmetry, consistent with our hypothesis that signals related to leftright spatial asymmetry reduced cutaneous reflex modulation. As stated, split-belt locomotion changed the temporal phasing index in intact cats, consistent with a more asymmetric temporal pattern, with no effect in spinal cats. The main difference is that intact cats can consciously perceive the altered pattern generated by split-belt locomotion, whereas spinal cats cannot. We propose that the greater change in temporal phasing in intact cats during split-belt locomotion is due to supraspinal/volitional factors.

\section{Spinal mechanism modulates cutaneous reflexes during split-belt locomotion}

Our results indicate that a spinal mechanism reduced cutaneous reflex modulation during split-belt locomotion compared with tied-belt locomotion because we observed similar results in intact and spinal cats. These results suggest that spinal networks have the ability to recognize left-right asymmetries in the locomotor pattern, potentially indicating gait instability. Conversely, perceived threats to stability and increased cutaneous feedback gain reported in humans (Haridas et al., 2005, 2006) is most likely mediated by cerebral cortical mechanisms (Pijnappels et al., 1998; Christensen et al., 1999).

What signals the reduction in cutaneous reflex modulation and by what spinal mechanism? Although we can only speculate, sensory feedback signaling left-right asymmetry most likely triggers the reduction in cutaneous reflex modulation during splitbelt locomotion. This feedback signal can come from different sources. Because reflex modulation more closely correlated with spatial symmetry in intact and spinal cats compared with temporal symmetry, the source of sensory feedback probably comes from leg position/loading signals. Position signals could relate to whole leg position, such as limb orientation angles (Shen and Poppele, 1995), or to more localized specific joints/segments, such as hip angle (Grillner and Rossignol, 1978). We recently showed how sensory feedback related to hip position/limb loading differed between slow and fast limbs during split-belt locomotion and how these can regulate phase transitions in spinal cats (Frigon et al., 2017).

Presynaptic inhibition of SP nerve afferents is a likely mechanism for the decreased cutaneous reflex modulation, because it was observed in all muscles ipsilateral and contralateral to the stimulation during split-belt locomotion. The simplest explanation for this generalized decrease is reduced neurotransmitter released from primary afferent terminals (Burke, 1999; Rudomin 
and Schmidt, 1999). We propose that a mechanism determines whether the locomotor pattern is symmetric by using or comparing sensory feedback from the left and right legs, thus altering the state of the spinal network. The modulatory mechanism could be controlled by left and right central pattern generators and/or more directly from sensory afferents providing position/loading feedback from the legs. We also cannot exclude that the mechanism is part of the spinal locomotor central pattern generator, which then sets the tonic level of presynaptic inhibition task dependently. Figure 11 illustrates potential mechanisms involved in cutaneous reflex modulation during split-belt locomotion via signals related to leg position/loading. We also cannot exclude that the state of spinal neurons differs between tied-belt and splitbelt locomotion. For instance, higher synchronous activity of spinal neurons would lead to larger reflex responses to a given sensory input.

\section{Concluding remarks}

In conclusion, we have shown a spinal-mediated task-dependent modulation of cutaneous reflexes during locomotion. Specifically, split-belt locomotion reduced cutaneous reflex modulation in ipsilateral and contralateral hindlimb muscles of intact and spinal cats compared with matched tied-belt speeds. We proposed that sensory feedback from the limbs signals spinal networks of a left-right asymmetry and a potentially unstable gait. In turn, the spinal networks reduce incoming inputs to prevent them from perturbing or destabilizing an already precarious gait. From a clinical perspective, the results suggest that restoring left-right symmetry in pathological conditions could normalize interactions between afferents inputs from the legs and spinal networks controlling locomotion, potentially improving functional recovery.

\section{References}

Abourachid A, Herbin M, Hackert R, Maes L, Martin V (2007) Experimental study of coordination patterns during unsteady locomotion in mammals. J Exp Biol 210:366-372. CrossRef Medline

Abraham LD, Marks WB, Loeb GE (1985) The distal hindlimb musculature of the cat: cutaneous reflexes during locomotion. Exp Brain Res 58:594603. CrossRef Medline

Bernard G, Bouyer L, Provencher J, Rossignol S (2007) Study of cutaneous reflex compensation during locomotion after nerve section in the cat. J Neurophysiol 97:4173-4185. CrossRef Medline

Bretzner F, Drew T (2005) Motor cortical modulation of cutaneous reflex responses in the hindlimb of the intact cat. J Neurophysiol 94:673-687. CrossRef Medline

Buford JA, Smith JL (1993) Adaptive control for backward quadrupedal walking. III. stumbling corrective reactions and cutaneous reflex sensitivity. J Neurophysiol 70:1102-1114. CrossRef Medline

Burke RE (1999) The use of state-dependent modulation of spinal reflexes as a tool to investigate the organization of spinal interneurons. Exp Brain Res 128:263-277. CrossRef Medline

Christensen LO, Morita H, Petersen N, Nielsen J (1999) Evidence suggesting that a transcortical reflex pathway contributes to cutaneous reflexes in the tibialis anterior muscle during walking in man. Exp Brain Res 124:5968. CrossRef Medline

Courtine G, Schieppati M (2003a) Human walking along a curved path. I. Body trajectory, segment orientation and the effect of vision. Eur J Neurosci 18:177-190. CrossRef Medline

Courtine G, Schieppati M (2003b) Human walking along a curved path. II. gait features and EMG patterns. Eur J Neurosci 18:191-205. CrossRef Medline

Dambreville C, Labarre A, Thibaudier Y, Hurteau MF, Frigon A (2015) The spinal control of locomotion and step-to-step variability in left-right symmetry from slow to moderate speeds. J Neurophysiol 114:1119-1128. CrossRef Medline

Dambreville C, Charest J, Thibaudier Y, Hurteau MF, Kuczynski V, Grenier
G, Frigon A (2016) Adaptive muscle plasticity of a remaining agonist following denervation of its close synergists in a model of complete spinal cord injury. J Neurophysiol 116:1366-1374. CrossRef Medline

D’Angelo G, Thibaudier Y, Telonio A, Hurteau MF, Kuczynski V, Dambreville C, Frigon A (2014) Modulation of phase durations, phase variations and temporal coordination of the four limbs during quadrupedal split-belt locomotion in intact adult cats. J Neurophysiol 112:1825-1837. CrossRef Medline

Dietz V, Zijlstra W, Duysens J (1994) Human neuronal interlimb coordination during split-belt locomotion. Exp Brain Res 101:513-520. Medline

Duysens J, Loeb GE (1980) Modulation of ipsi- and contralateral reflex responses in unrestrained walking cats. J Neurophysiol 44:1024-1037. CrossRef Medline

Duysens J, Stein RB (1978) Reflexes induced by nerve stimulation in walking cats with implanted cuff electrodes. Exp Brain Res 32:213-224. Medline

Duysens J, Tax AA, Trippel M, Dietz V (1993) Increased amplitude of cutaneous reflexes during human running as compared to standing. Brain Res 613:230-238. CrossRef Medline

Duysens J, Bastiaanse CM, Smits-Engelsman BC, Dietz V (2004) Gait acts as a gate for reflexes from the foot. Can J Physiol Pharmacol 82:715-722. CrossRef Medline

Duysens J, Potocanac Z, Hegeman J, Verschueren S, McFadyen BJ (2012) Split-second decisions on a split belt: does simulated limping affect obstacle avoidance? Exp Brain Res 223:33-42. CrossRef Medline

Eldridge L (1984) Vertebral location of cord segments innervating cat hind limb musculature. Exp Neurol 83:193-198. CrossRef Medline

Forssberg H (1979) Stumbling corrective reaction: a phase-dependent compensatory reaction during locomotion. J Neurophysiol 42:936-953. CrossRef Medline

Forssberg H, Grillner S, Rossignol S (1975) Phase dependent reflex reversal during walking in chronic spinal cats. Brain Res 85:103-107. CrossRef Medline

Forssberg H, Grillner S, Rossignol S (1977) Phasic gain control of reflexes from the dorsum of the paw during spinal locomotion. Brain Res 132: 121-139. CrossRef Medline

Forssberg H, Grillner S, Halbertsma J, Rossignol S (1980) The locomotion of the low spinal cat. II. Interlimb coordination. Acta Physiol Scand 108: 283-295. CrossRef Medline

Frigon A, Rossignol S (2007) Plasticity of reflexes from the foot during locomotion after denervating ankle extensors in intact cats. J Neurophysiol 98:2122-2132. CrossRef Medline

Frigon A, Rossignol S (2008a) Adaptive changes of the locomotor pattern and cutaneous reflexes during locomotion studied in the same cats before and after spinalization. J Physiol 586:2927-2945. CrossRef Medline

Frigon A, Rossignol S (2008b) Short-latency crossed inhibitory responses in extensor muscles during locomotion in the cat. J Neurophysiol 99:989_ 998. CrossRef Medline

Frigon A, Barrière G, Leblond H, Rossignol S (2009) Asymmetric changes in cutaneous reflexes after a partial spinal lesion and retention following spinalization during locomotion in the cat. J Neurophysiol 102:26672680. CrossRef Medline

Frigon A, Hurteau MF, Thibaudier Y, Leblond H, Telonio A, D'Angelo G (2013) Split-belt walking alters the relationship between locomotor phases and cycle duration across speeds in intact and chronic spinalized adult cats. J Neurosci 33:8559-8566. CrossRef Medline

Frigon A, D'Angelo G, Thibaudier Y, Hurteau MF, Telonio A, Kuczynski V, Dambreville C (2014) Speed-dependent modulation of phase variations on a step-by-step basis and its impact on the consistency of interlimb coordination during quadrupedal locomotion in intact adult cats. J Neurophysiol 111:1885-1902. CrossRef Medline

Frigon A, Thibaudier Y, Hurteau MF (2015) Modulation of forelimb and hindlimb muscle activity during quadrupedal tied-belt and split-belt locomotion in intact cats. Neuroscience 290:266-278. CrossRef Medline

Frigon A, Desrochers É, Thibaudier Y, Hurteau MF, Dambreville C (2017) Left-right coordination from simple to extreme conditions during splitbelt locomotion in the chronic spinal adult cat. J Physiol 595:341-361. CrossRef Medline

Goetz L, Piallat B, Thibaudier Y, Montigon O, David O, Chabardès S (2012) A non-human primate model of bipedal locomotion under restrained condition allowing gait studies and single unit brain recordings. J Neurosci Methods 204:306-317. CrossRef Medline 
Greenland S (2008) Multiple comparisons and association selection in general epidemiology. Int J Epidemiol 37:430-434. CrossRef Medline

Greenland S, Robins JM (1991) Empirical-bayes adjustments for multiple comparisons are sometimes useful. Epidemiology 2:244-251. CrossRef Medline

Grillner S, Rossignol S (1978) On the initiation of the swing phase of locomotion in chronic spinal cats. Brain Res 146:269-277. CrossRef Medline

Halbertsma JM (1983) The stride cycle of the cat: the modelling of locomotion by computerized analysis of automatic recordings. Acta Physiol Scand Suppl 521:1-75. Medline

Handžić I, Reed KB (2015) Perception of gait patterns that deviate from normal and symmetric biped locomotion. Front Psychol 6:199. CrossRef Medline

Haridas C, Zehr EP (2003) Coordinated interlimb compensatory responses to electrical stimulation of cutaneous nerves in the hand and foot during walking. J Neurophysiol 90:2850-2861. CrossRef Medline

Haridas C, Zehr EP, Misiaszek JE (2005) Postural uncertainty leads to dynamic control of cutaneous reflexes from the foot during human walking. Brain Res 1062:48-62. CrossRef Medline

Haridas C, Zehr EP, Misiaszek JE (2006) Context-dependent modulation of interlimb cutaneous reflexes in arm muscles as a function of stability threat during walking. J Neurophysiol 96:3096-3103. CrossRef Medline

Harnie J, Côté-Sarrazin C, Hurteau MF, Desrochers E, Doelman A, Amhis N, Frigon A (2018) The modulation of locomotor speed is maintained following partial denervation of ankle extensors in spinal cats. J Neurophysiol 120:1274-1285. CrossRef Medline

Harris-Love ML, Forrester LW, Macko RF, Silver KH, Smith GV (2001) Hemiparetic gait parameters in overground versus treadmill walking. Neurorehabil Neural Repair 15:105-112. CrossRef Medline

Hoogkamer W, Bruijn SM, Duysens J (2014) Stride length asymmetry in split-belt locomotion. Gait Posture 39:652-654. CrossRef Medline

Hoogkamer W, Bruijn SM, Potocanac Z, Van Calenbergh F, Swinnen SP, Duysens J (2015) Gait asymmetry during early split-belt walking is related to perception of belt speed difference. J Neurophysiol 114:17051712. CrossRef Medline

Hurteau MF, Thibaudier Y, Dambreville C, Desaulniers C, Frigon A (2015) Effect of stimulating the lumbar skin caudal to a complete spinal cord injury on hindlimb locomotion. J Neurophysiol 113:669-676. CrossRef Medline

Hurteau MF, Thibaudier Y, Dambreville C, Chraibi A, Desrochers E, Telonio A, Frigon A (2017) Non-linear modulation of cutaneous reflexes with increasing speed of locomotion in spinal cats. J Neurosci 37:3896-3912. CrossRef Medline

Hurteau MF, Thibaudier Y, Dambreville C, Danner SM, Rybak IA, Frigon A (2018) Intralimb and interlimb cutaneous reflexes during locomotion in the intact cat. J Neurosci 38:4104-4122. CrossRef Medline

Ioannidis JPA (2018) The proposal to lower P value thresholds to .005. JAMA 319:1429-1430. CrossRef Medline

Jiang W, Drew T (1996) Effects of bilateral lesions of the dorsolateral funiculi and dorsal columns at the level of the low thoracic spinal cord on the control of locomotion in the adult cat. I. Treadmill walking. J Neurophysiol 76:849-866. CrossRef Medline

Jones CA, Yang JF (1994) Reflex behavior during walking in incomplete spinal-cord-injured subjects. Exp Neurol 128:239-248. CrossRef Medline

Kuczynski V, Telonio A, Thibaudier Y, Hurteau MF, Dambreville C, Desrochers E, Doelman A, Ross D, Frigon A (2017) Lack of adaptation during prolonged split-belt locomotion in the intact and spinal cat. J Physiol 595:5987-6006. CrossRef Medline

Kulagin AS, Shik ML (1970) Interaction of symmetric extremities during controlled locomotion [Article in Russian]. Biofizika 15:164-170. Medline

LaBella LA, Niechaj A, Rossignol S (1992) Low-threshold, short-latency cutaneous reflexes during fictive locomotion in the "semi-chronic" spinal cat. Exp Brain Res 91:236-248. Medline

Llewellyn M, Yang JF, Prochazka A (1990) Human H-reflexes are smaller in difficult beam walking than in normal treadmill walking. Exp Brain Res 83:22-28. Medline

Loeb GE (1993) The distal hindlimb musculature of the cat: interanimal variability of locomotor activity and cutaneous reflexes. Exp Brain Res 96:125-140. Medline
Matthews PB (1986) Observations on the automatic compensation of reflex gain on varying the pre-existing level of motor discharge in man. J Physiol 374:73-90. CrossRef Medline

McFadyen BJ, Hegeman J, Duysens J (2009) Dual task effects for asymmetric stepping on a split-belt treadmill. Gait Posture 30:340-344. CrossRef Medline

Panek I, Bui T, Wright AT, Brownstone RM (2014) Cutaneous afferent regulation of motor function. Acta Neurobiol Exp (Wars) 74:158-171. Medline

Pijnappels M, Van Wezel BM, Colombo G, Dietz V, Duysens J (1998) Cortical facilitation of cutaneous reflexes in leg muscles during human gait. Brain Res 787:149-153. CrossRef Medline

Poole C (1991) Multiple comparisons? No problem! Epidemiology 2:241243. Medline

Pratt CA, Chanaud CM, Loeb GE (1991) Functionally complex muscles of the cat hindlimb. IV. Intramuscular distribution of movement command signals and cutaneous reflexes in broad, bifunctional thigh muscles. Exp Brain Res 85:281-299. CrossRef Medline

Prochazka A, Sontag KH, Wand P (1978) Motor reactions to perturbations of gait: proprioceptive and somesthetic involvement. Neurosci Lett 7:3539. CrossRef Medline

Prokop T, Berger W, Zijlstra W, Dietz V (1995) Adaptational and learning processes during human split-belt locomotion: interaction between central mechanisms and afferent input. Exp Brain Res 106:449-456. Medline

Quevedo J, Stecina K, Gosgnach S, McCrea DA (2005a) Stumbling corrective reaction during fictive locomotion in the cat. J Neurophysiol 94: 2045-2052. CrossRef Medline

Quevedo J, Stecina K, McCrea DA (2005b) Intracellular analysis of reflex pathways underlying the stumbling corrective reaction during fictive locomotion in the cat. J Neurophysiol 94:2053-2062. CrossRef Medline

Reisman DS, Block HJ, Bastian AJ (2005) Interlimb coordination during locomotion: what can be adapted and stored? J Neurophysiol 94:24032415. CrossRef Medline

Rossignol S, Frigon A (2011) Recovery of locomotion after spinal cord injury: some facts and mechanisms. Annu Rev Neurosci 34:413-440. CrossRef Medline

Rossignol S, Dubuc R, Gossard JP (2006) Dynamic sensorimotor interactions in locomotion. Physiol Rev 86:89-154. CrossRef Medline

Rothman KJ (1990) No adjustments are needed for multiple comparisons. Epidemiology 1:43-46. CrossRef Medline

Rudomin P, Schmidt RF (1999) Presynaptic inhibition in the vertebrate spinal cord revisited. Exp Brain Res 129:1-37. CrossRef Medline

Schillings AM, Van Wezel BM, Duysens J (1996) Mechanically induced stumbling during human treadmill walking. J Neurosci Methods 67:1117. CrossRef Medline

Shen L, Poppele RE (1995) Kinematic analysis of cat hindlimb stepping. J Neurophysiol 74:2266-2280. CrossRef Medline

Shimamura M, Livingston RB (1963) Longitudinal conduction systems serving spinal and brain-stem coordination. J Neurophysiol 26:258-272. CrossRef Medline

Sinkjaer T, Toft E, Hansen HJ (1995) H-reflex modulation during gait in multiple sclerosis patients with spasticity. Acta Neurol Scand 91:239-246. CrossRef Medline

Sinkjaer T, Andersen JB, Nielsen JF (1996) Impaired stretch reflex and joint torque modulation during spastic gait in multiple sclerosis patients. J Neurol 243:566-574. CrossRef Medline

Thibaudier Y, Frigon A (2014) Spatiotemporal control of interlimb coordination during transverse split-belt locomotion with 1:1 or 2:1 coupling patterns in intact adult cats. J Neurophysiol 112:2006-2018. CrossRef Medline

Torres-Oviedo G, Vasudevan E, Malone L, Bastian AJ (2011) Locomotor adaptation. Prog Brain Res 191:65-74. CrossRef Medline

Van Wezel BM, Ottenhoff FA, Duysens J (1997) Dynamic control of location-specific information in tactile cutaneous reflexes from the foot during human walking. J Neurosci 17:3804-3814. CrossRef Medline

Yang JF, Fung J, Edamura M, Blunt R, Stein RB, Barbeau H (1991) H-reflex modulation during walking in spastic paretic subjects. Can J Neurol Sci 18:443-452. CrossRef Medline

Zehr EP, Stein RB (1999) What functions do reflexes serve during human locomotion? Prog Neurobiol 58:185-205. CrossRef Medline 